Institute for Research on Poverty

Discussion Paper no. 1079-96

\title{
Differential Mortality and Wealth Accumulation
}

\author{
Orazio P. Attanasio \\ Universita' di Bologna, NBER, and Institute for Fiscal Studies \\ and \\ Hilary W. Hoynes \\ University of California-Berkeley, and NBER
}

January 1996

We thank Dan McFadden, Paul Ruud, Frank Wolak, and seminar participants at the University of California-Berkeley, Dartmouth College, Stanford University, and the University of Wisconsin-Madison for useful comments. An early version of this paper was presented at the 1993 NBER Summer Institute on the Economics of Aging in Cambridge, Mass. Harish Chand provided excellent research assistance.

Financial support was received from the Institute for Industrial Relations, the Institute for Business and Economic Research, and the National Institute on Aging. Computing support was provided by the Econometrics Laboratory at UC-Berkeley. 


\begin{abstract}
An issue central to the life-cycle theory of consumer behavior, and to many policy questions, is asset accumulation and decumulation. One of the main implications of the life-cycle model is that assets are decumulated in the last part of life. Most empirical studies of asset accumulation use cross-sectional data to estimate mean or median wealth-age profiles, but the use of cross sections to estimate the age profile of assets is full of pitfalls. If, for example, wealth and mortality are related, in that poorer individuals die at a younger age, one overestimates the last part of the wealth-age profile when using cross-sectional data because means (or other measures of location) are taken over a population which becomes "richer" as it ages. In our examination of the effect of differential mortality on cross-sectional estimates of wealth-age profiles, we quantify the dependence of mortality rates on wealth and then use these estimates to "correct" wealth-age profiles for sample selection due to differential mortality. We estimate mortality rates as a function of wealth and age for a sample of married couples drawn from the Survey of Income and Program Participation (SIPP). Our results show that accounting for differential mortality produces wealth profiles with significantly more dissaving among the elderly.
\end{abstract}




\section{Differential Mortality and Wealth Accumulation}

\section{INTRODUCTION}

The issue of asset accumulation and decumulation is central to the life-cycle theory of consumer behavior and to many policy questions. One of the main implications of some versions of the life-cycle model is that assets are decumulated in the last part of life (see Modigliani and Brumberg 1954; Modigliani and Ando 1957). Despite the large amount of research devoted to establishing whether people actually decumulate assets in the last part of the life cycle, no conclusive evidence has yet emerged (see review by Hurd 1990; also see Blinder et al. 1983; Jianakoplos et al. 1989; King and Dicks-Mireaux 1982; Mirer 1979). This is partially due to the fact that wealth data are scarce and of poor quality; furthermore, it is very difficult to follow the same individuals over time.

The ideal data for estimating wealth-age profiles would consist of panel data with a broad-based age sample whose wealth data is collected over a long period of time. However, data of this sort is not available. ${ }^{1}$ Typically, cross-sectional data is used to estimate mean or median wealth-age profiles, but the use of short panels or cross sections to estimate the age profile of assets is full of pitfalls. As Shorrocks (1975) first pointed out, the use of a single cross section can be very misleading because of cohort effects. If younger generations are in lifetime terms "richer" than older ones, identifying the age profile of wealth with the cross-section profile can give the illusion of asset decumulation even when this does not occur. The use of cohort techniques can overcome this problem. ${ }^{2}$

${ }^{1}$ There were two cohort-based datasets produced during the 1970s and 1980s which collected information on wealth. The Retirement History Survey collected wealth data every 2 years over a 10year period for a sample of men aged 58-61 in 1979. The National Longitudinal Survey (NLS) of Older Men started in 1966 and followed a cohort aged 45-59 for 17 years. Wealth data is available at regular intervals, but the definition of wealth is not consistent over the panel.

${ }^{2}$ Attanasio (1993) uses synthetic panels constructed using data from the Consumer Expenditure Survey to estimate wealth-age profiles. He finds mild evidence of decumulation in the last part of the life cycle. 
Although the use of synthetic panels can control for cohort effects, the use of cross-sectional data can introduce a bias of a different nature. If wealth and mortality are related, in that poorer individuals die at a younger age, one overestimates the last part of the wealth-age profile when using cross-sectional data because means (or other measures of location) are taken over a population that becomes "richer" as it ages. Similar problems apply to the estimation of income and consumption age profiles.

The bias due to differential mortality was raised by Shorrocks (1975), who applied some rough corrections for differential mortality and found that they made a substantial difference, in that the corrected data showed asset decumulation in the last part of life, while the uncorrected did not. ${ }^{3}$ Jianakoplos et al. (1989) estimate wealth profiles for a subset of their panel who survive the entire 15-year period and find that accounting for differential mortality implies greater dissaving among the elderly than that found in a cross section.

Our approach is to quantify the dependence of mortality rates on wealth and to use these estimates to "correct" wealth-age profiles for sample selection due to differential mortality. This is difficult both because of the lack of reliable data and because of some conceptual problems, which we will discus below. We estimate mortality rates as a function of wealth and age for a sample of married couples drawn from the Survey of Income and Program Participation (SIPP), a survey that contains information on wealth and on death over a two-year period. We use these estimates to correct mean and median wealth-age profiles for sample selection induced by differential mortality. Our results show that accounting for differential mortality produces wealth profiles with significantly more dissaving among the elderly.

Most of the extensive literature on estimating the economic determinants of mortality focuses on income as the measure of resources (for example, see Kitagawa and Hauser 1973; Duleep 1987) while a few studies have explored the role of wealth. Jianakoplos et al. (1989), using the NLS Older Men's Cohort, show that elderly individuals in the bottom two deciles of the wealth distribution exhibit mortality rates

${ }^{3}$ Shorrocks used a sample of estate records along with wealth-specific actuarial rates to correct the observed wealth profiles. 
three times as large as individuals in the top decile. Duleep (1987) shows that, even after allowing for some endogeneity problems (to be discussed below) and after controlling for education, there is a relationship between mortality and income. More recently, Menchik (1993) uses the NLS Older Men's Cohort to estimate the probability of death between 1966 and 1983 as a function of the level of wealth in 1966 and other covariates. He finds an inverse relationship between wealth and mortality which persists in the presence of controls for health, permanent income, and background variables.

Having identified the relationship between wealth and mortality, our method for correcting wealthage profiles for differential mortality is fairly simple. One way to understand the distortion induced by differential mortality in wealth-age profiles is in terms of a sample selection process. If an observation has a certain probability of being included in the sample (the probability of surviving to a certain age), we will weight that observation by the reciprocal of that probability. Hence, the main contribution of the paper is to parameterize and estimate the dependence of mortality on wealth. These mortality rates are then used to construct weights used for correcting wealth profiles. The method we propose to estimate wealth-related death probabilities and to correct estimated wealth profiles addresses problems that, to the best of our knowledge, have not been tackled before. This study integrates the two literatures on differential mortality and wealth accumulation.

The paper is organized as follows. In Section 2 we discuss the endogeneity problems that plague the estimation of wealth-specific mortality rates and that are relevant for most, if not all, available datasets. Section 3 outlines two different methodologies to estimate wealth-specific mortality rates and Section 4 explains how the two different sets of estimates can be used to correct estimated wealth-age profiles. Section 5 is a brief description of the SIPP data; Section 6 presents the empirical model. Section 7 presents mortality estimates, and in Section 8 we apply these estimates to correct estimated wealth profiles. Our conclusions appear in Section 9.

\section{MORTALITY AND WEALTH: ENDOGENEITY PROBLEMS}


There are at least three reasons why wealth, which is very likely to affect mortality, cannot be considered as an exogenous variable for mortality. First, while it is likely that low wealth implies higher mortality, both wealth and mortality may be related to a third factor: health. If this is the case, there could be an inverse relationship: poor health (and therefore higher mortality) may jeopardize wealth accumulation. This issue is discussed at length by Duleep (1987), who focuses primarily on the relationship between mortality and income.

The second source of simultaneity between wealth and mortality arises from life-cycle considerations. The wealth accumulation behavior of individuals with different life expectancies could, conceivably, be different. Within a life-cycle model, individuals who expect to live a shorter life should, all else being equal, decumulate their wealth after retirement at a faster pace (Davies 1981). ${ }^{4}$

The final source of simultaneity is more subtle and is a consequence of the fact that differential mortality changes the wealth distribution of a given cohort as it ages. Suppose that individuals of a given age face a mortality rate that depends on their "lifetime" wealth, or on some other wealth measure which is age invariant. Further suppose that, at any given age, mortality rates are inversely related to the relative position in the distribution of lifetime resources. Of course, observed wealth is determined by the optimal accumulation plan and by total lifetime resources. However, at a given point in time, the relative position of individuals in the distribution of current wealth (within their cohort) is not equivalent to their relative position in the distribution of lifetime resources. This is both because wealth accumulation and decumulation behavior can be different for different classes, as noted above, and because differential mortality will change the wealth distribution of the population. Therefore, while observed wealth is likely to be correlated with mortality, it is not the "right" variable for identifying the structural relationship between wealth and mortality. Even though one can condition on current observed wealth when estimating

${ }^{4}$ Hurd and McGarry (1993) show that people seem to be aware of differential mortality, that is, they assess their own chances quite well. 
mortality rates, the correction of age-wealth profiles for differential mortality must take into account this kind of endogeneity explicitly.

Here we focus mainly on how to take into account the third source of endogeneity, and we give conditions on the nature of behavioral heterogeneity which are sufficient to make our analysis robust to the presence of the problems of the second source (discussed above). While we recognize the importance of the first source, we ignore it in this paper. To begin, we consider an example that will make the nature of the third source more transparent.

Suppose that the distribution of observed wealth at a benchmark age $a^{b}$ is equivalent to the distribution of lifetime resources. Further assume that mortality rates at each age depend on which wealth class an individual belongs to at age $a^{b}$. In particular, suppose that mortality at each age depends on whether an individual's wealth is above or below the median for their cohort at age $a^{b}$, and that individuals below the median have higher mortality rates. ${ }^{5}$

Whether an individual has less than median wealth at age $a^{b}+1$ is not the correct determinant of mortality between ages $a^{b}+1$ and $a^{b}+2$. The reason is precisely that differential mortality by wealth classes at age $a^{b}$ changes the distribution of wealth at subsequent ages as poorer individuals are more likely to die. The number of individuals below the median at age $a^{b}$ who survive to age $a^{b}+1$ is lower than the number of survivors above the median. Therefore, to estimate mortality rates at age $a^{b}+1$, we have to know the characteristics of the survivors at $a^{b}+1$, which, in turn, depend on mortality rates at age $a^{b}$.

Differential mortality by wealth classes is not the only problem in the estimation of wealth-age profiles. Several other issues should and can be considered. For some of these issues, techniques similar to the one we propose can be used. Just to mention a few, one might consider that attrition is reportedly stronger for richer households (Jianakoplos et al.1989) and that wealth accumulation can be related to changes in family composition, such as divorce and widowhood (Burkhauser et al. 1988; Hurd and Wise

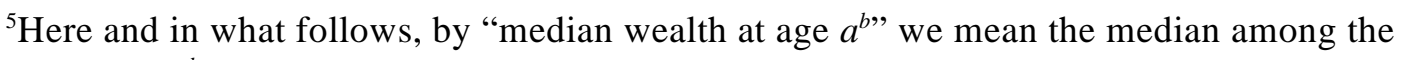
individuals of age $a^{b}$. 
1989). All of these phenomena are also likely to present the same endogeneity problems discussed for differential mortality.

\section{ESTIMATION OF WEALTH-DEPENDENT MORTALITY RATES}

Correcting observed cross-sectional wealth profiles requires two steps. In the first step, we estimate mortality rates as a function of wealth. In the second step, these estimated mortality rates are used to construct weights representing the cumulative probability of surviving to the current age given observed wealth. In this section, we outline two methods for estimating the dependence of mortality on wealth. The two models we consider differ in the definition of the conditioning variable that captures the effects of wealth on mortality. The first model conditions on observed current wealth, while the second conditions on wealth at a benchmark age. For each model we propose a correction methodology for wealth-age profiles discussed in the next section. ${ }^{6}$

In most age ranges, the probability of death is low. Accordingly, to estimate mortality rates with precision, one needs to observe a reasonably large number of individuals over time. Our analysis uses data from the Survey of Income and Program Participation (SIPP), a relatively large dataset that follows

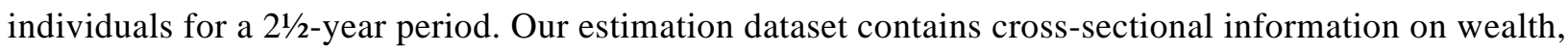
age, and other covariates, along with information on any deaths that occur over the short panel. ${ }^{7}$

Our empirical model relies on the following key assumptions. ${ }^{8}$ First, we assume that mortality rates depend on relative wealth, as opposed to the absolute level of wealth. Relative wealth is defined as

${ }^{6}$ In our data, we do not observe wealth at a baseline age. Because of this, we shall show that the difference between the two methods can be interpreted as functional form differences.

${ }^{7}$ SIPP panels contain two observations on wealth, taken 12 months apart. We do not use the second wealth inventory because it is not sufficient to identify the evolution of wealth over time.

${ }^{8}$ In this section, for expositional simplicity, we refer to single individuals, whereas in the empirical application we consider married couples as the unit of observation. In Section 5, we discuss how to amend the approach outlined below to consider couples rather than individuals. 
the wealth percentile within a cohort. Age-specific wealth percentile is preferred to wealth levels because the distribution of wealth is highly skewed and is typically top-coded in survey data. Further, the use of relative wealth is a natural way to capture the notion that having a given level of wealth as a 30 -year-old is very different from the same level of wealth at age 70 . This assumption, however, implies that if the population gets richer over time (uniformly), then mortality rates do not change. While there is evidence of falling mortality rates over time, the available data do not cover a sufficiently long period of time to separate trend effects from age effects.

Second, we make a crucial assumption about the nature of the heterogeneity of wealthaccumulation behavior. This is necessary if we want to avoid simultaneously modeling mortality rates and wealth accumulation. The assumption we make, which we label the "non-crossing assumption," is that the ranking of individuals in terms of wealth does not change with age after the benchmark age. This is a strong assumption. Notice, however, that if wealth-accumulation behavior differs because of differential mortality, it is likely to differ in a way that is consistent with our assumption. If poorer individuals decumulate assets more quickly after retirement because of shorter life expectancy, they cannot "overtake"-in terms of wealth—richer individuals.

Hence, the alternative is to estimate a two-equation simultaneous model—one equation modeling the evolution of wealth, and the other modeling mortality rates as a function of wealth. In order to estimate this model, we would need to have a long panel dataset containing wealth information at many points in the life cycle, but, as we have noted, sufficient data for a broad age range are not available. The non-crossing assumption, together with the assumption that mortality depends on relative wealth, allows us to use the observed data on current wealth, along with our empirical model of mortality rates, to estimate a person's (within-cohort) wealth percentile for periods not observed in the data. This assumption is required for both of the modeling approaches we propose.

Third, we assume that there are no cohort effects on mortality (beside those captured indirectly by wealth and other controls), an assumption made exclusively for expositional simplicity and because we are 
using data from a relatively short period in which cohort effects would be difficult to identify. Fourth, we assume that there are no differences in mortality rates across wealth classes before the benchmark age, $a^{b}$, which, in our empirical analysis, we assume to be age 50. Although this may not hold, especially at very young ages, mortality rates are sufficiently low for younger individuals that our data contain very few deaths prior to age 50. Finally, we assume that the only determinants of mortality are age and wealth. The introduction of additional determinants of mortality rates is a nontrivial problem and is discussed at the end of the section.

\subsection{Conditioning on Current Wealth}

The first model assumes that mortality rates are a function of the observed wealth percentile. In particular, we assume that the probability of death at any age depends on a polynomial in wealth percentile at the current age. Let $a$ be the current age and $w p(a)$ be the wealth percentile at the current age. Let $P S(a, w p(a))$ represent the probability of surviving from age $a$ to age $a+1$ for someone in wealth percentile $w p$ at age $a$. Given data on age and wealth percentile and a functional form for the survival probabilities, the estimation of this model is straightforward. The use of these estimates to correct estimated wealth-age profiles is, however, more involved.

The weight to be given to an individual of age $a$ in the computation of mean or median age-wealth profiles depends on the cumulative probability of surviving between the benchmark age $a^{b}$ and $a$, which in turn depends on the wealth position at those ages. ${ }^{9}$ While one observes the wealth position of an individual at the current age $a$, one does not observe the wealth position at ages $a^{b}$ through $a^{b}-1$. These positions have to be inferred from the position at age $a$ and from the previously estimated model of mortality. The expressions for the correction are given below.

\subsection{Conditioning on Wealth at the Benchmark Age}

${ }^{9}$ The probability of surviving to age $a^{b}$ is ignored since we assume that there is no differential mortality prior to the benchmark age. 
The second model assumes that mortality at any given age depends on a polynomial in wealth percentile at the benchmark age $a^{b}$. This assumption captures the idea that mortality is likely to be related to "lifetime resources" and, for the individuals belonging to the same "lifetime wealth" class, changes smoothly with age. If $w p\left(a^{b}\right)$ is the wealth percentile at the benchmark age, then $P S\left(a, w p\left(a^{b}\right)\right)$ represents the probability of surviving from age $a$ to age $a+1$ for someone in wealth percentile $w p$ at age $a^{b}$.

The difficulty in estimating this model is that we do not observe the wealth distribution at age $a^{b}$. This distribution has to be inferred from the current wealth distribution and the model that determines mortality between the benchmark and the current age. In other words, we want to establish a relationship between the (observed) current age-wealth distribution and the unobserved wealth distribution at the benchmark age.

Consider the simple example introduced in Section 2. In that example, the survival probability depends on whether an individual has wealth above or below the median at age $a^{b}$. Further suppose that the probability of survival between ages $a^{b}$ and $a^{b}+1$ is 1.0 for those above the median and 0.5 for those below. Half of those below the median and all those above the median survive the year. Therefore, the individuals below the median at age $a^{b}$ now represent only one-third of the wealth distribution of the population at age $a^{b}+1$. The non-crossing assumption implies that ranking of the individuals does not change from year to year. Therefore, if we observe a sample of persons of age $a^{b}+1$, those in the bottom third of the wealth distribution at age $a^{b}+1$ belong to the lower wealth group at the benchmark age, while those above the 33rd percentile are from the upper wealth group. The non-crossing assumption plays a crucial role in inferring previous wealth percentile here and in the model conditioning on current wealth.

To generalize, consider the probability of survival to be a function of wealth percentile at the benchmark age, $P S\left(a, w p\left(a^{b}\right)\right)$. If we denote $W P\left(a^{b}+1, y\right)$ to be the wealth percentile at age $a^{b}+1$, which corresponds to wealth percentile $y$ at the benchmark age $a^{b}, y$ solves the following expression: ${ }^{10}$

\footnotetext{
${ }^{10}$ Using this notation, the previous example showed that $W P\left(a^{b}+1, .5\right)=0.33$.
} 


$$
\mathrm{WP}\left(\mathrm{a}^{\mathrm{b}}+1, y\right)=\frac{\int_{0}^{\mathrm{y}} \operatorname{PS}\left(\mathrm{a}^{\mathrm{b}}, \mathrm{x}\right) \mathrm{dx}}{\int_{0}^{1} \operatorname{PS}\left(\mathrm{a}^{\mathrm{b}}, \mathrm{x}\right) \mathrm{dx}} .
$$

The denominator represents the total fraction of the population that survives between ages $a^{b}$ and $a^{b}+1$. The numerator is the fraction of the population, up to wealth percentile $y$, which survives to the next period. The ratio of the two gives the wealth percentile at age $a^{b}+1$, which reveals the $y$ th wealth percentile at the benchmark age.

Using cumulative probabilities of survival, we can construct the expression which defines the wealth percentile at any age $a^{b}+k$ which identifies the group corresponding to the wealth percentile $y$ at age $a^{b}$,

$$
W P\left(a^{b}+k, y\right)=\frac{\int_{0}^{y} \prod_{i=0}^{k-1} \operatorname{PS}\left(a^{b}+i, x\right) d x}{\int_{0}^{1} \prod_{i=0}^{k-1} \operatorname{PS}\left(a^{b}+i, x\right) d x} .
$$

The denominator represents the total fraction of the population that survives between ages $a^{b}$ and $a^{b}+k$. The numerator is the fraction of the population, up to the benchmark wealth percentile $y$, which survives $k$ periods. The ratio of the two gives the wealth percentile at age $a^{b}+k$, which reveals the $y$ th wealth percentile at the benchmark age. There is just one integrand in this expression because the survival probabilities are each a function of the wealth percentile at the benchmark age. Using (1), we can assign $w p\left(a^{b}\right)$ to individuals given current wealth, $w p\left(a^{b}+k\right)$, and age, $a^{b}+k$.

Consideration of equation (1) makes clear that, ultimately, the difference between the two models we use is only a difference in functional forms. Both models relate mortality rates to current wealth and current age. In the second model, however, the relationship is extremely nonlinear: mortality is a function 
of $w p\left(a^{b}\right)$, which, in turn, is a nonlinear function of observed wealth, as given by equation (1). This complication arises because the second model conditions on wealth at the benchmark age, which is unobservable, rather than on current wealth. The use of the first model to correct wealth-age profiles, however, involves the use of an equation similar to (1), as we need to infer the wealth percentiles at all ages between the benchmark age and the current age. ${ }^{11}$

\subsection{Adding Controls}

In addition to wealth, one might want to control for other factors that affect mortality. It should be stressed that to correct estimated wealth-age profiles for the effect of differential mortality, one does not need to control for additional variables that might be important determinants of mortality: the specification of the selection mechanism and its relation to the variable of interest (wealth) is sufficient for such a purpose. However, there are other reasons for which one would want to consider additional controls. For instance, it might be interesting to establish whether wealth affects mortality over and above the effect that other variables correlated with wealth might have. Furthermore, controlling for some additional factors might yield more efficient estimates of the effect of wealth on mortality. An example of the first variable might be education or race: it might be interesting to establish whether wealthier individuals within an education class exhibit different mortality rates or whether the effect of wealth proxies the effect that education might have on mortality (see, for instance, Duleep 1987). An example of the second kind of variable is the difference in age between the head and the spouse: given that we define "death of a household" as the death of one of the spouses and that "age" is the age of the head, consideration of the age difference between the head and the spouse might add useful information that can improve the efficiency of our estimates.

${ }^{11}$ Notice that, if the population is large enough, (1) is a deterministic and not a probabilistic equation that relates the unobservable $y$ to the observed wealth percentile at the current age, $w p\left(a^{b}+k\right)$. 
In this subsection, we consider controls that do not vary with age: within the framework we use, the only variable that changes over time is age. The effect of the other variables (wealth at a benchmark age, additional controls) is to modify the survival probability each individual faces at each age.

The consideration of determinants of mortality other than age and wealth does not pose any problems for the estimation of the first model considered. One can add a covariate $z$ to the survival rate-PS(a,wp $(a), z)$. The model that conditions on the distribution of wealth at the benchmark age, however, is more complicated. Similar complications arise for the first model when correcting the wealth-age profiles.

Even if one assumes that the effect of various controls is the same across wealth and age groups, that is, that there are no interactions between wealth, age, and the controls one introduces, one has to model the effects of within-group heterogeneity carefully. The basic problem is similar to that considered above. Given observations at age $a^{b}+k$ and their relative position in the distribution of wealth, one has to establish, for each observation, the wealth percentile at the benchmark age. This depends on the survival rates of each wealth percentile and on the composition of the population in terms of the control variable at each wealth percentile at the previous age.

An example will clarify the difficulties related to the introduction of controls. Consider the previous example, in which mortality at any given age depends on whether an individual is below or above the median at the benchmark age. Suppose that because of differential access to health services, mortality also depends on the race of an individual. As before, given the observed wealth position at the current age, we have to establish the wealth position at the benchmark age. To do so, we have to take into account not only differential mortality by wealth groups but also differential mortality by race. It is therefore necessary to have information on the joint distribution of wealth and race at the benchmark age. ${ }^{12}$

\footnotetext{
${ }^{12}$ Note that if all blacks were below median wealth and all whites above the median at the benchmark age, it would not be possible to identify the influences of the two variables separately.
} 
In general, adding a covariate to the model has significant data and computational demands. First, as illustrated above, we need to know the distribution of the covariate and wealth percentile at the benchmark age, information that is generally not available. However, as shown in Appendix A, the distribution of current wealth and the covariate can be combined with the empirical model for the survival probabilities to infer the distribution at the benchmark age. Appendix A also shows that this adds to the computational burdens of the model. Due to these difficulties, we leave the estimation with additional controls to future work.

\section{CORRECTING WEALTH-AGE PROFILES}

In this section we outline the methods we use to correct estimated wealth-age profiles for differential mortality by wealth groups. We consider the correction procedure for both models of mortality presented in Section 3. It turns out that the correction for the first model is more involved, as it requires us to infer, for each observation, the wealth percentile at all ages between the benchmark and the current age. For the second model we need to infer only the wealth percentile at the benchmark age.

We are interested in constructing a correction procedure that can be easily applied to various measures of location and, in particular, to means and quantiles. Consider the problem in a standard sample selection model. If mortality is inversely related to wealth, then the persons we observe at older ages are the wealthier members of their cohort. We want to weight the observations to reflect this sample selection. The main idea, used for both models, is to assign to each observation a weight proportional to the inverse of the probability of having survived from the benchmark age up to the observed age. If poorer individuals are more likely to die at a younger age, they will receive a greater weight. The difference in the weights assigned to different wealth groups will presumably increase with age. Having assigned the relevant weight to each observation, the correction for various measures of location is simple: for means (or conditional means) we take weighted averages and for percentiles, we cumulate the weights until we obtain the desired percentile. 
Before going into details about construction of the weights, it is worth pausing to discuss the interpretation of the corrected profiles. In the case of percentiles the interpretation is straightforward. Suppose we are interested in tracking the wealth profile for the person with median wealth at the benchmark age. Because of differential mortality, such an individual will not be at the median at subsequent ages. The corrected profile allows us to follow the median individual over time. The ability to follow the same individual over time is obviously crucial to evaluate life-cycle behavior and to determine the extent of asset decumulation.

For the mean, the interpretation is a bit more involved. Mean wealth at a certain age is not necessarily equal to the wealth of any individual of that age. Uncorrected mean wealth is the average wealth of the population of individuals of a certain age currently alive. There are two reasons why such an average changes with age: because of wealth accumulation or decumulation and because of changes in the composition of the population. The correction we perform aims at isolating the former and removing the effects of the latter.

Let us start with the model that conditions on current wealth. The non-crossing assumption is crucial for the development of the correction scheme proposed here in the same way it was for inferring $w p\left(a^{b}\right)$ for estimating the mortality rates. The weight for an observation of age $a^{b}+k$ is the inverse of the cumulative probability of survival from age $a^{b}$ to age $a^{b}+k$,

$$
\frac{1}{\prod_{i=0}^{k-1} P S\left(a^{b}+i, w p\left(a^{b}+i\right)\right)}
$$

The main issue we have to solve is the following. In this model, we assume that survival probabilities depend on the wealth percentile at the current age. Therefore, to compute the appropriate weight for an individual age $a^{b}+k$, we have to establish the wealth percentile at all ages from $a^{b}$ to $a^{b}+k-1$. Yet we observe wealth only at the current age. Therefore, we have to use the distribution of current wealth and the estimates for the survival rates to infer the wealth percentile for the previous ages. For such a purpose we 
can use expressions substantially analogous to equation (1). For example, if we observe a person aged 58 in the 25 th wealth percentile, we can use the estimates of the mortality rates in equation (1) to derive the person's wealth percentile at age 57. Given that, we can use (1) again to derive the wealth percentile at age 56. The wealth distribution at all previous ages can be derived in this recursive manner.

The correction of wealth profiles relevant for the second model is much more straightforward. The weight in this case is

$$
\frac{1}{\prod_{i=0}^{k-1} P S\left(a^{b}+i, w p\left(a^{b}\right)\right)},
$$

where $w p\left(a^{b}\right)$ is the wealth percentile at age $a^{b}$. The formulas used to derive the percentiles that define the wealth percentiles at the benchmark age can be used again. Computing the weights is straightforward, once the wealth percentile for each observation has been established.

\section{THE DATA}

The data are drawn from SIPP's 1984 and 1987 panels. Each of the SIPP panels consists of nationally representative stratified random samples of between 12,000 and 21,000 families. Each household is interviewed three times a year and provides information on labor force participation, sources and amounts of income, household composition, and demographics for each member of the household for each of the previous four months. Typically, there are a total of eight interviews (called "waves") over the 32-month period comprising the panel. In addition to the core questions asked at each interview, data on household wealth is collected at two points in the 32-month panel. ${ }^{13}$

${ }^{13}$ The 1984 panel was the first of the SIPP panels and each year since then a new SIPP panel has been sampled. The 1984 panel contains 21,000 families and the 1987 panel contains 12,000 families. The number of waves in the SIPP panels have varied due to funding availability. The 1984 panel had eight waves and the 1987 panel had seven waves. 
The estimation sample includes all married couples where the head of household is age 50 or greater. ${ }^{14}$ We restrict our sample to those age 50 and over because we assume that wealth has no effect on mortality prior to that age. There are several reasons to limit our analysis to married couples. First, wealth is a family, not an individual, concept. Second, the non-crossing assumption may be less valid if we allow for multiple family types. For example, changes in family composition due to divorce or widowhood are likely to lead to dramatic changes in wealth and income (Burkhauser et al. 1988; Hurd and Wise 1989). Further, never-married men or women may have a different shape to their wealth profiles compared to married couples because, for example, of the absence of costs of educating offspring. Third, the mortality model would be complicated by the existence of multiple family types: single men, single women, and married couples.

The consideration of households (married couples) rather than individuals poses some conceptual and practical problems. First, we redefine the event of "death." In this paper we focus on married couples and define death as the event that one of the two spouses dies. That is, we are estimating wealth profiles for married couples and correcting for the sample selection imposed by differential mortality. ${ }^{15}$ To be consistent with the model, we include only couples that were already married at the benchmark age. ${ }^{16}$ The estimation sample consists of 7,025 couples.

${ }^{14}$ Specifically, the couple must be married as of the first interview and either the husband or wife must be the head of household. Further, a family is dropped if they do not have any wealth data (for example, if they attrit before the fourth wave when wealth is collected) or if they have negative wealth.

${ }^{15}$ Married couples can also "leave" the sample by divorce or separation. In principle, one can address this problem in a way similar to mortality. In practice, very few couples divorce after age 50, which is our benchmark age. In our sample, less than 1 percent of couples divorce during the panel, making it difficult to identify the determinants of divorce. Households can also attrit from the sample over the panel. Jianakoplos et al. (1989) show that while poor households are subject to higher mortality, richer households are subject to higher attrition. We do not model the determinants of attrition, but treat them as right-censored spells.

${ }^{16}$ Marital history information is available on the SIPP. An analysis of the 1984 SIPP shows that over 95 percent of the married couples over age 50 were married to their current spouse at age 50 . The results are not sensitive to this sample selection. 
The SIPP data allow for identification of the death of either spouse at four-month intervals. In each of the interviews, data is provided identifying the reason that a person left the household, if applicable. Death is one of these routes. During the $2 \frac{1}{2}$ years of the panel, about 4 percent (or 281) of men die and about 2 percent (or 126) of women die. These data can be used to form one-year death rates by age and sex which can be compared to the life tables, based on vital statistic data (Social Security Administration 1992). The SIPP mortality rates compare quite favorably to the life-table data, as shown in Table 1. Annual mortality rates for men vary from 0.9 percent for those age 50-54 to 5.9 percent among those age 75-79. Rates for women vary from 0.5 percent for ages 50-54 to 4.0 percent for ages $75-79$. With a few exceptions, these rates fall between the 1980 and 1990 life-table estimates. ${ }^{17}$

A full inventory of household wealth is collected at two points during the SIPP panel, one at the fourth interview and one at the seventh interview. Data is collected for financial wealth (interest- earning assets, stocks, and mutual funds), IRA/Keogh accounts, home equity, vehicle equity, business equity, and other real estate. Curtin et al. (1989) show that the SIPP data compare favorably to other household survey measures of wealth, which all suffer from underreporting of some asset types, such as stocks. ${ }^{18}$ The characteristics of various wealth measures for our sample are shown in Table 2. Home equity and interestearning assets represent the most important components of household wealth. About 83 percent of all married

${ }^{17}$ Life-table estimates vary by calendar year because of cohort or time effects. During this period, the reductions in mortality rates were uniform across age and sex classes.

${ }^{18}$ The Survey of Consumer Finances is found to be the best survey for measuring household wealth, in part because of the oversampling of the wealthy. The quality of the SIPP wealth data was comparable to that found in the Panel Study of Income Dynamics (PSID). 


\section{TABLE 1}

Mortality Rates by Age and Sex Comparison of 1984 and 1987 SIPP to U.S. Life Tables

\begin{tabular}{lccc}
\hline & & & \\
& & & \\
Men & & & \\
& & & \\
$50-54$ & 0.0092 & Life Table & \\
$55-59$ & 0.0129 & 0.0094 & 0.0077 \\
$60-64$ & 0.0208 & 0.0145 & 0.0121 \\
$65-69$ & 0.0313 & 0.0220 & 0.0188 \\
$70-74$ & 0.0476 & 0.0342 & 0.0296 \\
$75-79$ & 0.0594 & 0.0502 & 0.0444 \\
& & 0.0734 & 0.0678 \\
Women & & & \\
$50-54$ & 0.0051 & 0.0050 & 0.0043 \\
$55-59$ & 0.0069 & 0.0075 & 0.0068 \\
$60-64$ & 0.0122 & 0.0113 & 0.0108 \\
$65-69$ & 0.0225 & 0.0172 & 0.0167 \\
$70-74$ & 0.0269 & 0.0262 & 0.0252 \\
$75-79$ & 0.0397 & 0.0418 & 0.0393 \\
\hline
\end{tabular}

Source: Data for columns two and three are from Social Security Administration 1992.

Note: Mortality rates represent the probability of death over a 12-month period.

aAuthors' tabulation of the SIPP. The SIPP data include the survival status of each survey member at 4-month intervals. A 1-year death probability is formed by taking the ratio of the number of people who die at a given age to the number of people "at risk of dying" at that age. 
TABLE 2

\section{Components of Household Wealth, 1984 and 1987 SIPP: Married Couple Families with Head $\geq \mathbf{5 0}$}

\begin{tabular}{|c|c|c|c|c|c|c|}
\hline & \multirow[b]{2}{*}{ Mean } & \multirow[b]{2}{*}{$\begin{array}{c}\text { Percent } \\
\text { Non-Zero } \\
\end{array}$} & \multicolumn{4}{|c|}{ Households with Non-Zero Amounts } \\
\hline & & & $\begin{array}{c}25 \text { th } \\
\text { Percentile }\end{array}$ & Median & $\begin{array}{c}\text { 75th } \\
\text { Percentile }\end{array}$ & Mean \\
\hline \multicolumn{7}{|l|}{ Components of Household Wealth } \\
\hline Interest earning assets & 23798 & 79.4 & 2958 & 12000 & 40000 & 29988 \\
\hline Stocks and mutual funds & 14550 & 25.0 & 2500 & 9000 & 32744 & 58275 \\
\hline Home equity & 54298 & 82.9 & 34563 & 54573 & 81860 & 65461 \\
\hline Vehicle equity & 6263 & 89.6 & 2550 & 5525 & 9550 & 6987 \\
\hline Business equity & 8547 & 11.7 & 5000 & 25240 & 95000 & 73043 \\
\hline Other real estate & 18150 & 26.9 & 11824 & 35000 & 77312 & 67497 \\
\hline Other assets & 9635 & 63.2 & 311 & 1000 & 3500 & 15238 \\
\hline IRAs/Keoghs & 4149 & 32.9 & 4400 & 8400 & 15000 & 12622 \\
\hline \multicolumn{7}{|l|}{ Measures of Household Wealth } \\
\hline (1) Total financial wealth & 47977 & 87.5 & 3297 & 15462 & 52753 & 54848 \\
\hline (2) Financial assets + home equity & 102281 & 91.9 & 39999 & 74000 & 129198 & 111331 \\
\hline (3) Total non-retirement wealth & 135241 & 93.3 & 48479 & 91549 & 167175 & 144938 \\
\hline (4) Total net worth & 137466 & 93.3 & 48248 & 93000 & 171135 & 147322 \\
\hline
\end{tabular}

Source: Authors' tabulations of 1984 and 1987 SIPP. Sample consists of all married couples with head of household greater than or equal to age 50. See text for details of sample selection. All dollar amounts are in 1984 dollars.

Wealth definitions: Definition (1) includes interest-earning assets (savings account, CDs, money market accounts, and bonds), equity in stocks and mutual funds, and other assets (checking accounts, savings bonds). Definition (2) adds home equity to the measure in (1). Definition (3) includes the components in (2) plus vehicle equity, business equity, and other real estate equity. Definition (4) adds deposits in IRA/Keogh accounts and subtracts unsecured debt. 
couples over age 50 have home equity and 80 percent have interest-earning assets totaling, on average, $\$ 78,000$. Four measures of financial wealth are summarized in Table 2. Our analysis uses the most inclusive measure, total net worth, which includes financial equity, home equity, business equity, and IRA/Keogh accounts less any unsecured debt. We concentrate on this measure because it is closest to the desired concept of lifetime resources that influence mortality rates. Further, the non-crossing assumption is more likely to hold with a more inclusive measure. ${ }^{19}$ Table 3 show how the estimates of two measures of wealth vary with age of the head.

Each couple's wealth percentile is assigned within 5-year age cohorts based on the age of the head of household. When pooling the 1984 and 1987 data, a deflator is used to convert the dollar amounts in the two surveys. Because of bunching in the data, we assign to the highest wealth percentile within the group all families that "tie." 20

Table 4 gives summary statistics for the estimation sample. About 6 percent of the sample experience a death of the husband or wife over the course of the panel. The average age of husbands is 63 , compared to 59 among the wives. Household net worth averages $\$ 137,466$ and the median is $\$ 93,000$.

Figure 1 shows mean and median wealth profiles by age of head of household. Both wealth distributions show some evidence of declining assets among the elderly. The more comprehensive measure, household net worth, shows more of a decline than does total financial wealth. Overall, the median profile is much more flat than the mean profiles.

${ }^{19} \mathrm{We}$ find similar results when we use financial assets as the definition of wealth.

${ }^{20}$ The only sizable bunching in the data is among families reporting zero wealth. About 8 percent of married couples in our sample report zero wealth. In that case, each couple with zero wealth is assigned to wealth percentile 8 . 
TABLE 3

\section{Household Wealth by Age of Head of Household: Married Couples in 1984 and 1987 SIPP}

\begin{tabular}{|c|c|c|c|c|c|c|}
\hline & $\begin{array}{l}\text { Number of } \\
\text { Observations }\end{array}$ & Mean & $\begin{array}{c}25 \text { th } \\
\text { Percentile }\end{array}$ & Median & $\begin{array}{c}75 \text { th } \\
\text { Percentile }\end{array}$ & Maximum \\
\hline \multicolumn{7}{|c|}{ Wealth Definition (1): Total Financial Wealth } \\
\hline Age of Head & & & & & & \\
\hline $\begin{array}{l}<25 \\
25-34\end{array}$ & $\begin{array}{r}634 \\
3705\end{array}$ & $\begin{array}{l}2237 \\
7797\end{array}$ & $\begin{array}{r}20 \\
190\end{array}$ & $\begin{array}{r}487 \\
1300\end{array}$ & $\begin{array}{l}1819 \\
5420\end{array}$ & $\begin{array}{r}105212 \\
1252300\end{array}$ \\
\hline $35-44$ & 3770 & 18545 & 450 & 2943 & 12097 & 5257210 \\
\hline $45-49$ & 1593 & 28815 & 636 & 4199 & 18099 & 6074500 \\
\hline $50-54$ & 1432 & 39970 & 700 & 5500 & 25050 & 6582149 \\
\hline $55-59$ & 1458 & 35787 & 1000 & 8117 & 36200 & 1524300 \\
\hline $60-64$ & 1396 & 48337 & 1392 & 11958 & 46061 & 2207900 \\
\hline $65-69$ & 1135 & 60845 & 1799 & 15300 & 58938 & 6938000 \\
\hline $70-74$ & 764 & 61723 & 1550 & 16063 & 55490 & 5941737 \\
\hline $75-79$ & 504 & 59150 & 3719 & 27454 & 77609 & 894905 \\
\hline $80-84$ & 288 & 42873 & 709 & 13267 & 54573 & 764527 \\
\hline $85+$ & 48 & 36918 & 800 & 8050 & 55299 & 268099 \\
\hline \multicolumn{7}{|c|}{ Wealth Definition (4): Total Net Worth } \\
\hline Age of Head & & & & & & \\
\hline$<25$ & 634 & 15133 & 1400 & 4989 & 14605 & 365389 \\
\hline $25-34$ & 3705 & 43393 & 5155 & 19646 & 49603 & 1240238 \\
\hline $35-44$ & 3770 & 84875 & 18171 & 50969 & 103343 & 5431661 \\
\hline $45-49$ & 1593 & 116170 & 27374 & 70667 & 138335 & 6204319 \\
\hline $50-54$ & 1432 & 135285 & 36903 & 79728 & 148202 & 7301648 \\
\hline $55-59$ & 1458 & 134366 & 40479 & 88744 & 162000 & 2073200 \\
\hline 60-64 & 1396 & 147137 & 43174 & 92114 & 174885 & 2892267 \\
\hline $65-69$ & 1135 & 143910 & 38267 & 87500 & 168321 & 7757700 \\
\hline 70-74 & 764 & 139570 & 32961 & 81380 & 155420 & 6160903 \\
\hline 75-79 & 504 & 132167 & 41963 & 94055 & 166525 & 1242422 \\
\hline 80-84 & 288 & 105024 & 19478 & 70472 & 146227 & 819027 \\
\hline $85+$ & 48 & 79827 & 28255 & 63557 & 113962 & 291599 \\
\hline
\end{tabular}

Note: Authors' tabulations of 1984 and 1987 SIPP. Sample consists of all married couples present at the first interview who have data for household wealth. For explanation of wealth definitions see Table 2 notes. All dollar amounts are in 1984 dollars. 
TABLE 4

Means of Dataset for Mortality Rate Estimation: 1984 and 1987 SIPP

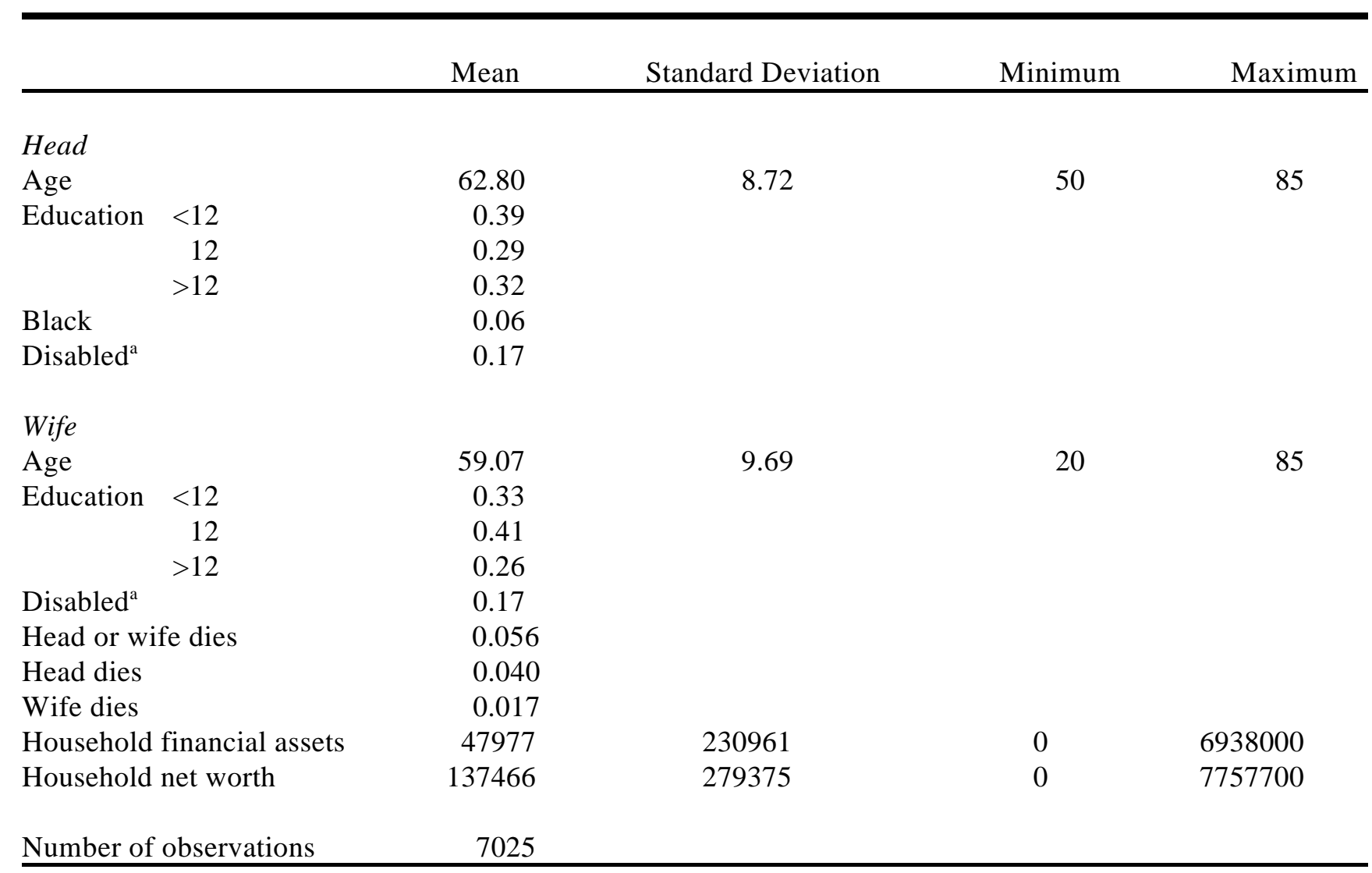

Note: Authors' tabulations of 1984 and 1987 SIPP. Sample consists of all married couples where the head of household is age 50 or greater at the first interview and who have data for household wealth. All dollar amounts are in 1984 dollars.

aisability status is available only for persons under the age of 65 . 
FIGURE 1

Mean and Median Household Wealth by Age of Head for Married Couples in the 1984 and 1987 SIPP

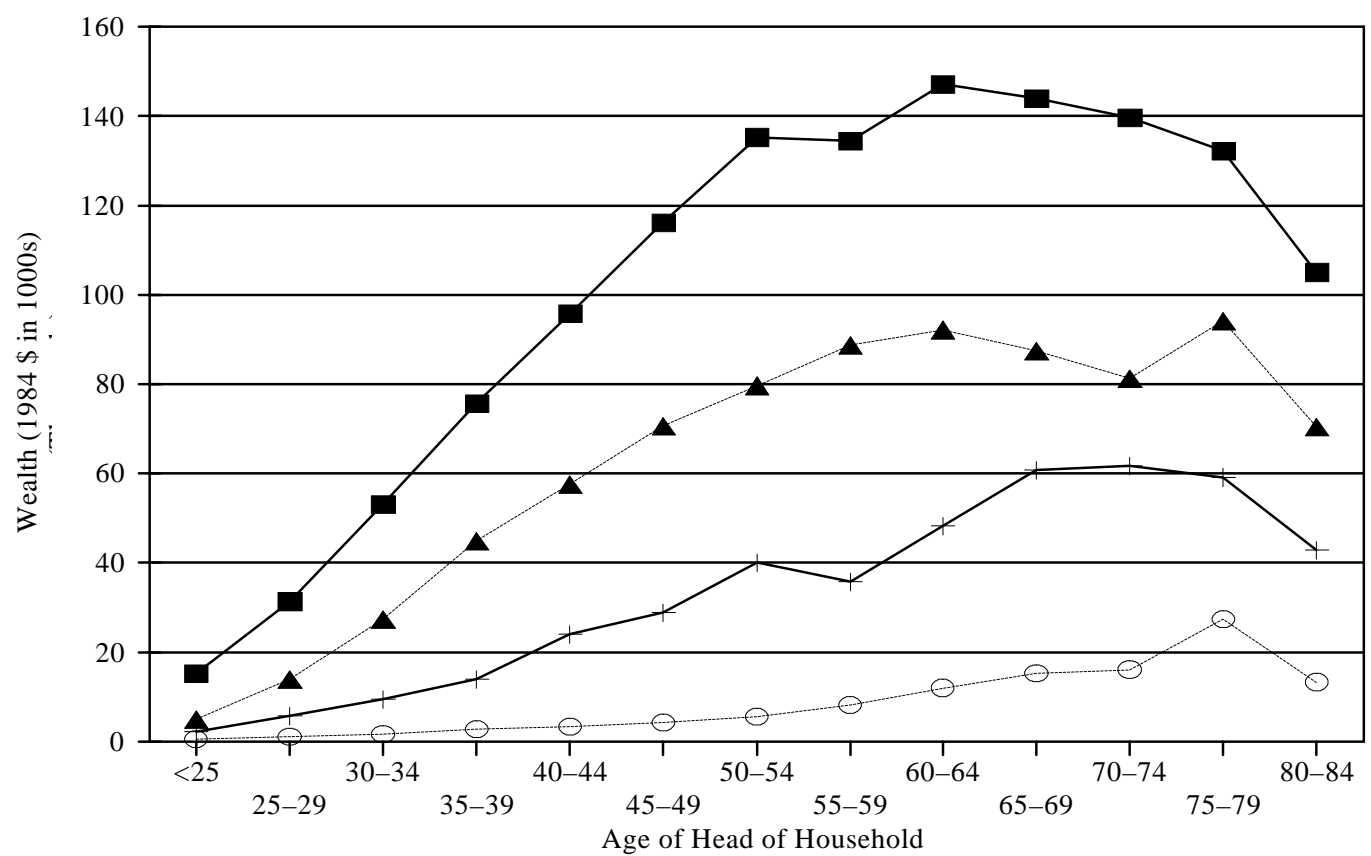

- Mean Total Wealth

$\triangle-$ Median Total Wealth —— Mean Financial

○- Median Financial 


\section{EMPIRICAL MODEL}

The mortality rates, introduced in Section 3, are estimated using a discrete time survival model (see Kalbfleisch and Prentice 1980). The SIPP data provide information on death of the head or spouse over 4-month periods. We use this information to estimate 4-month survival rates as a function of wealth percentile and age of head of household. The alternative is to estimate the probability that either the head or spouse dies at some point during the panel. Menchik (1993) uses this approach to estimate mortality rates over a 15-year period as a function of initial age and wealth. We choose to estimate 4- month mortality rates for several reasons. First, our correction model in Section 4 requires 1-year mortality (or survival) rates; 4-month probabilities are easy to aggregate up to the desired 12-month rates. Second, households may attrit at some point during the sample and the survival-model approach allows us to use all of the available information up until the point that they leave the sample. Third, as an extension of our basic survival model, we use a competing-risk model that allows for differential effects of age and wealth on the mortality rates of the husband and wife.

Let $P S(a, w p)$ represent a 1-year survival rate for someone age $a$ with wealth percentile $w p \cdot{ }^{21}$ Let $T$ be the total number of periods (4-month waves) that the married couple is observed with both spouses alive in the SIPP panel and let $\delta_{c}$ equal 1 if either spouse dies. The contribution of this couple to the likelihood function is the product of all of the 4- month transitions observed in the data:

$$
L=\left[\prod_{j=1}^{T-1} P S^{4}\left(a_{j}, w p\right)\right]\left[1-P S^{4}\left(a_{T-1}, w p\right)\right]^{\delta_{c}},
$$

where $P S^{4}\left(a_{j}, w p\right)$ is the probability of both the head and wife surviving over a 4-month period given age $a_{j}$ and wealth $w p .{ }^{22}$ Therefore, if a couple survives the entire 28 -month panel, there will be six survival rates

\footnotetext{
${ }^{21}$ The wealth percentile variable in this expression could be either wealth percentile at the current age or wealth percentile at the benchmark age.

${ }^{22}$ This estimation approach is used for estimating mortality rates as a function of current wealth or wealth at the benchmark age. For the model based on current wealth, $w p$ is the wealth percentile at the current age and $a_{j}$ is the age of head in period $j$. We use the first inventory of wealth, collected
} 
in this expression. If one spouse dies in between the fourth and fifth interview, for example, they will have three survival probabilities and one mortality probability. If a couple leaves the sample (attrits) between the fourth and fifth interviews, they will have three survival probabilities. Thus, attritions are treated as right-censored spells. One-year survival rates are constructed as the product of three sequential 4-month survival rates. $^{23}$

In this model, the dependent variable is death of the husband or wife. Yet the determinants of mortality may differ for the two spouses. We also estimated a competing risk-model specification where there are, in effect, two dependent variables: death of the head and death of the spouse. As in the above model, information is used only up to the point at which one of the spouses dies. ${ }^{24}$ Let $P S_{h}(a, w p)$ and $P S_{w}(a, w p)$ represent the 1-year survival rates for the husband and wife, respectively. A dummy variable of $\delta_{h}$ indicates a death of the husband and a dummy of $\delta_{w}$ indicates death of the wife. $T$ is defined as above. The couple's contribution to the likelihood function is the product of all of the 4- month transitions observed in the data for both the husband and wife, until one of them dies:

$$
L=\left[\prod_{j=1}^{T-1} P S_{h}^{4}\left(a_{j}, w p\right) P S_{w}^{4}\left(a_{j}, w p\right)\right]\left[1-P S_{h}^{4}\left(a_{T-1}, w p\right)\right]^{\delta_{h}}\left[1-P S_{w}^{4}\left(a_{T-1}, w p\right)\right]^{\delta_{w}}
$$

where $P S_{h}^{4}\left(a_{j}, w p\right)$ is the probability of the head and $P S_{w}^{4}\left(a_{j}, w p\right)$ the probability of the wife surviving over a 4-month period given age $a_{j}$ and wealth $w p$. One-year survival rates are constructed as the product of three sequential 4-month survival rates for the husband and wife.

We model the survival probabilities in a logit model,

$$
P S^{4}(a, w p)=\frac{1}{1+\exp (f(a, w p))},
$$

during the fourth interview, to construct this wealth measure. For the model based on benchmark age, $w p$ would represent wealth at age 50 .

${ }^{23}$ Specifically, $P S(a, w p)=P S^{4}(a, w p) * P S^{4}(a+.33, w p) * P S^{4}(a+.66, w p)$.

${ }^{24}$ In our dataset, there are twelve cases in which both the husband and wife died during the panel. 
where $f(a, w p)$ is a polynomial in age and wealth percentile. Age of the head of household (typically the husband) is used for age. The substantive results do not change if alternative functional forms are used.

\section{ESTIMATES OF MORTALITY RATES}

Before we turn to the regression results, we first explore the correlation between household wealth and death rates using the estimation dataset. Table 5 presents estimates of the probability of death of either the head or spouse by age of the head of household and wealth quartile. As in the regression results, wealth percentiles are assigned within the cohort defined by five-year age classes for the head of household. The number of observations for the five-year age classes average 1000 and range from 336 to 1458 . As expected, death rates increase with the age of the head of household. Further, death rates are inversely related to wealth quartile at all ages. Overall, mortality in the lowest wealth quartile is about three times as high as mortality in the highest wealth quartile. Most of the effect of wealth is shown in the high death rates among the lowest wealth quartile — the pattern between wealth and mortality risk is much less strong among the upper three wealth quartiles.

Our basic specification includes a cubic polynomial in wealth percentile, a linear age term, and a quadratic polynomial for the interaction between age and wealth percentile. ${ }^{25}$ The interaction terms allow for

${ }^{25}$ The results of specification tests show that this is the preferred specification of the polynomials. We cannot reject the hypothesis that the coefficients on higher degree polynomials in wealth, age, and the interaction terms are zero. 
TABLE 5

Probability of Death of Either Head or Spouse By Age of Head and Wealth Quartile

\begin{tabular}{|c|c|c|c|c|c|c|}
\hline & \multirow[b]{2}{*}{$\begin{array}{l}\text { Number of } \\
\text { Observations }\end{array}$} & \multirow[b]{2}{*}{$\begin{array}{c}\text { All } \\
\text { Couples } \\
\end{array}$} & \multicolumn{4}{|c|}{ Wealth Quartile } \\
\hline & & & Quartile 1 & Quartile 2 & Quartile 3 & Quartile 4 \\
\hline \multicolumn{7}{|c|}{ Age of Head } \\
\hline All & 7025 & 0.035 & 0.065 & 0.030 & 0.029 & 0.023 \\
\hline $50-54$ & 1432 & 0.009 & 0.024 & 0.009 & 0.005 & 0.002 \\
\hline $55-59$ & 1458 & 0.012 & 0.038 & 0.001 & 0.004 & 0.012 \\
\hline $60-64$ & 1396 & 0.026 & 0.042 & 0.020 & 0.025 & 0.021 \\
\hline $65-69$ & 1135 & 0.039 & 0.063 & 0.045 & 0.035 & 0.018 \\
\hline $70-74$ & 764 & 0.063 & 0.129 & 0.036 & 0.045 & 0.052 \\
\hline $75-79$ & 504 & 0.076 & 0.111 & 0.076 & 0.082 & 0.041 \\
\hline $80+$ & 336 & 0.121 & 0.195 & 0.137 & 0.104 & 0.067 \\
\hline
\end{tabular}

Note: Authors' tabulations of 1984 and 1987 SIPP. Sample consists of all married couples present at the first interview with head of household $\geq 50$ who have data on household wealth. For information on identifying death in the SIPP and a description of calculating 12-month mortality rates, see the notes to Table 1 . Wealth quartiles are age-specific. 
differential effects of wealth among different age groups. We also present a specification with a spline in wealth percentile to capture the concentration of wealth effects among low wealth levels highlighted in Table 5. We also present estimates for a competing risk model which allow for the determinants of death to differ among husbands and wives.

\subsection{Conditioning on Current Wealth}

Table 6 contains the estimates of the mortality rates for the model that conditions on current wealth percentile. Standard errors are in parentheses. The first model shows the results of the basic model of polynomial in wealth percentile and age. Most of the parameters are individually significant at the 5 percent level, and each of the polynomials is jointly significant. Given the difficulty in interpreting the coefficients from the logit model, we predict the mortality rates implied by the model for various age and wealth percentile levels. Figure 2 a shows the profiles for mortality rates of the couple by age of head of household for the 20th, 40th, 60th, and 80th percentiles of the wealth distribution. This figure shows that mortality rates increase with age and decrease with wealth percentile. At age 65 , the 1-year death rate is about 4 percent for the 20 th percentile compared to 1.5 percent for the 80 th percentile. At age 75 , the differential is 8 percent versus 4 percent. This can also be seen in Figure 2b, which shows mortality rates of the couple by wealth percentile for those age 55,65 , and $75 .{ }^{26}$ This figure shows that most of the variation in mortality rates is concentrated in the lowest wealth percentiles. Menchik (1993) and Jianakoplos et al. (1989) show that mortality rates in the bottom quartile are almost three times as high as mortality among the top decile. They also find most of the effects of differential mortality to be concentrated in the lowest quartile.

${ }^{26}$ The percentile profile begins at the 8 th percentile because of out-of-sample prediction problems. Recall that because of bunching at zero wealth, as much as 10 percent of the distribution-inwealth percentile is concentrated at the 10 th percentile. 
TABLE 6

Estimates for Mortality Rate Conditioning on Current Wealth

Married Couples, Head $\geq 50$

(1)

(2)

(3)

(4)

Non-Competing Risk Model Estimates

WP

$-19.773$

(6.334)

WP squared

31.197

(8.040)

WP cubed

$-14.575$

(3.447)

Age of head * WP

0.095

0.061

$(0.086)$

$(0.082)$

Age of head * WP squared

$-0.098$

$-0.067$

$(0.090)$

(0.086)

Age of head

0.074

0.082

(0.016)

(0.016)

$-7.517$

(1.111)

$\mathrm{WP}=<25$

$-6.571$

(1.153)

$-36.985$

$\mathrm{WP}=<25 * \mathrm{WP}$

(9.842)

77.877

$\mathrm{WP}=<25 * \mathrm{WP}$ squared

(26.685)

$-1.302$

(3.166)

2.354

(6.234)

Education of head $<12$

$-0.119$

(0.131)

0.067

(0.148)

Agediff $\leq-1$

0.552

$(0.170)$

Agediff 2-3

0.099

$(0.175)$

Agediff 4-6

0.108

$(0.163)$

Agediff 7+

0.032

(0.163)

Number of observations

7025

7025

7025

7025

Log likelihood

$-2032.8$

$-2023.8$

$-2031.8$

$-2026.0$

(table continues) 
TABLE 6, continued

(5)

Competing Risk Model

Probability of Death: Head

WP

$-13.594$

(6.446)

WP squared

15.381

(7.946)

WP cubed

$-5.278$

(3.399)

Age of head * WP

0.085

$(0.091)$

Age of head * WP squared

$-0.073$

$(0.097)$

Age of head

0.071

$(0.016)$

Constant

$-8.088$

(1.130)

\section{Probability of Death: Spouse}

WP

2.564

WP squared

(11.366)

3.890

(13.440)

WP cubed

$-4.358$

(5.243)

Age of head * WP

$-0.079$

$(0.149)$

Age of head * WP squared

0.031

$(0.147)$

Age of head

0.121

(0.032)

Constant

$-13.462$

Number of observations

Log likelihood

$-2358.9$

Note: These estimates are based on a discrete duration model where 4-month death probabilities are modeled using a logit specification. Standard errors are in parentheses. 
FIGURE 2

Probability of Death for Head or Spouse Conditioning on Current Wealth: Basic Model a. Probability by Age of Head and Selected Wealth Percentiles

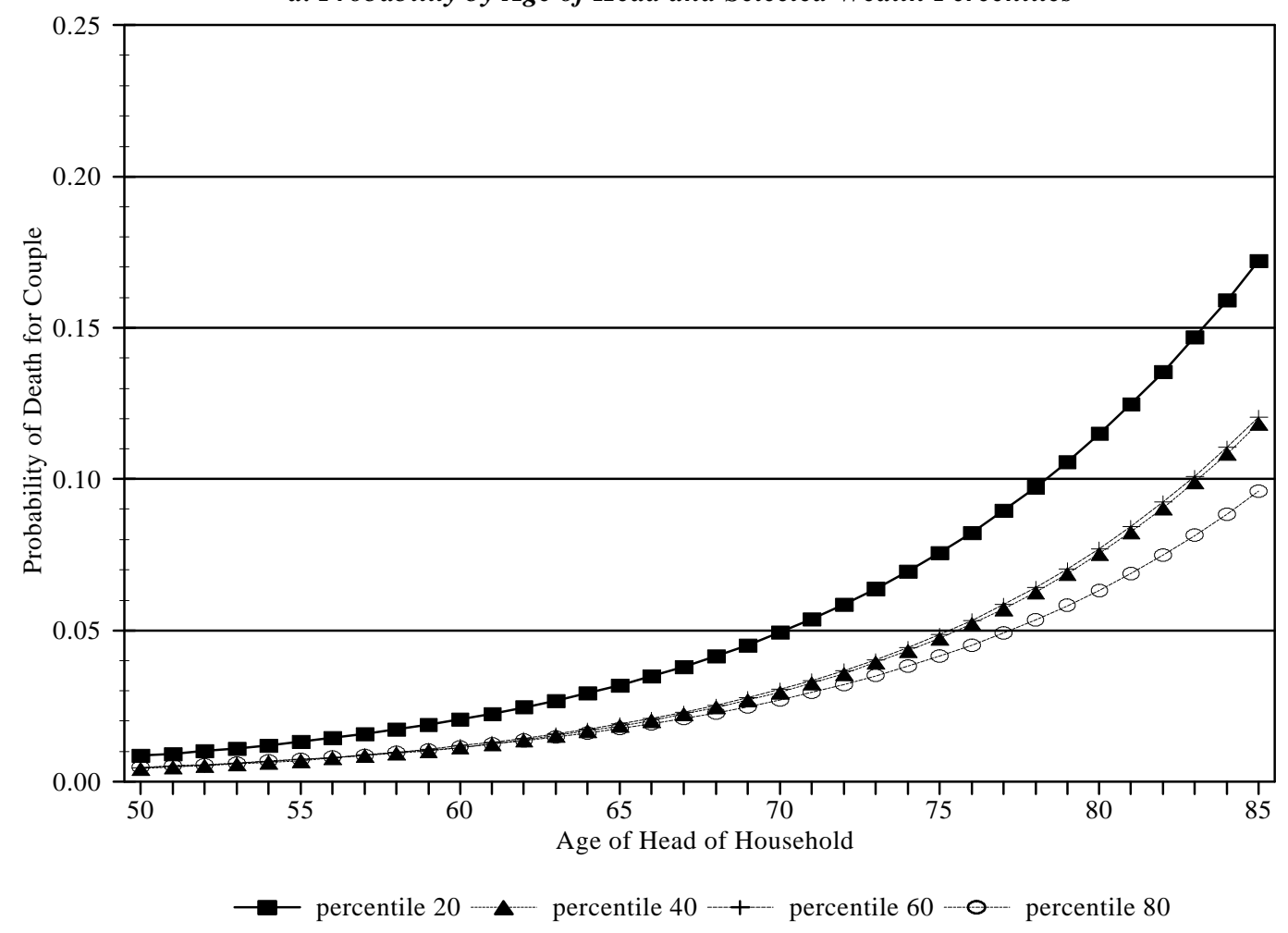

b. Probability by Wealth Percentile and Selected Ages

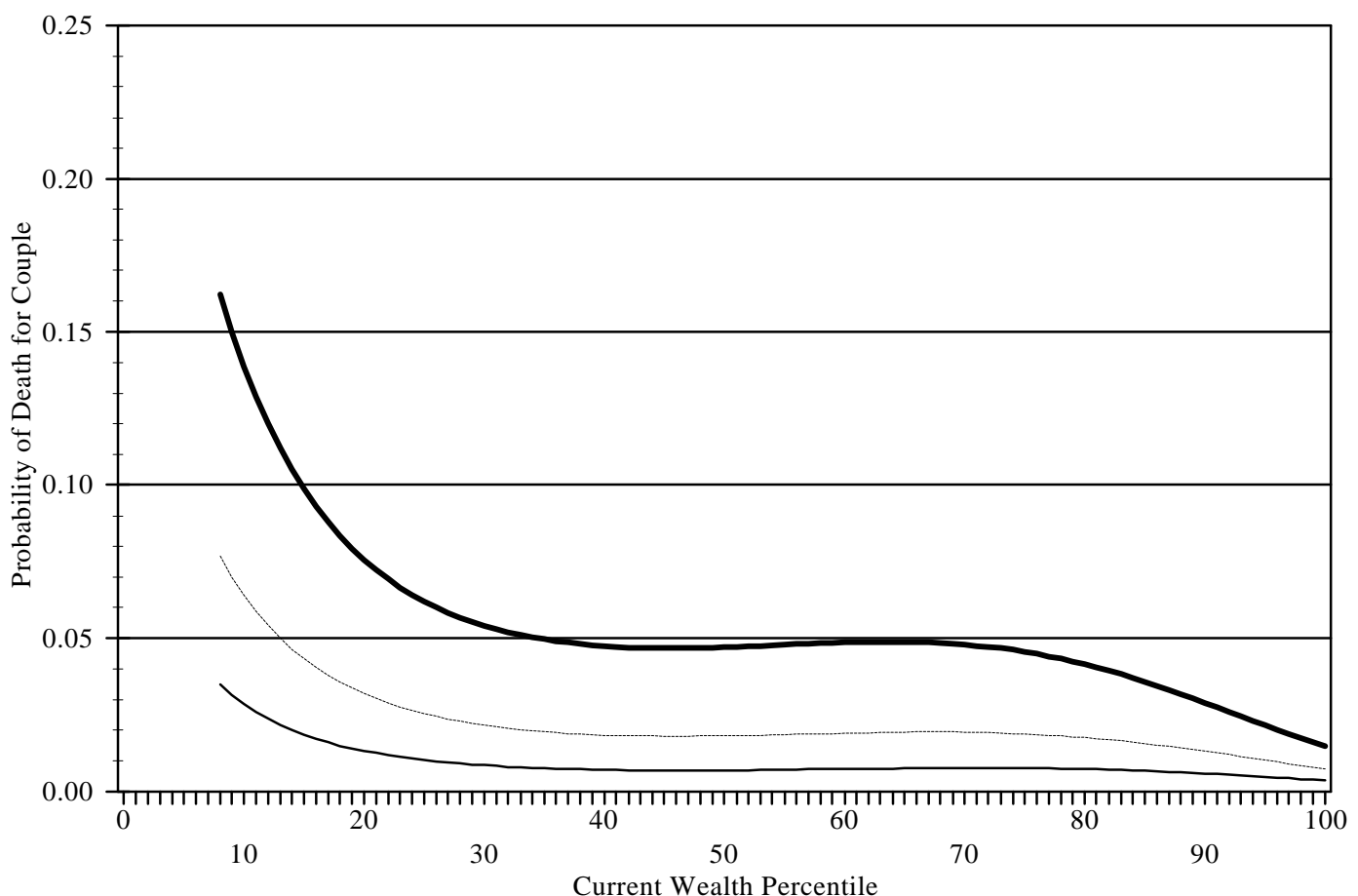

Current Wealth Percentile

$\longrightarrow$ age $55-$ age $65-$ age 75 
To capture the nonlinear effects of low wealth on the mortality rates, model (2) includes a spline in wealth percentile, with a quadratic above and below the 25 th percentile. ${ }^{27}$ The results show that the polynomial for low wealth levels is strongly significant and the polynomial at higher wealth levels is insignificant. The mortality rates based on these estimates, presented in Figures $3 \mathrm{a}$ and $3 \mathrm{~b}$, show that most of the effects of differential mortality are explained by very high death rates among the lowest groups. The profiles are quite flat after the 20th percentile. This may reflect the fact that the lowest persons in the low wealth groups have limited access to health services or that they have higher risk factors. Alternatively, previous poor health may have reduced wealth, which explains higher mortality risk.

The remaining specifications consider adding controls for education (model 3), age of the spouse (model 4), and estimating a competing risk model for death of the head or spouse (model 5). Controlling for wealth, the effect of education is both small and statistically insignificant. Menchik (1993) finds that education has no effect on mortality once wealth is controlled for. Duleep (1987) finds that the effect of education is large, although she controlled only for income and not wealth. Due to high correlation between the age of the head and spouse, adding age of the spouse does not affect the predicted mortality rates. The competing risk model shows that the determinants of death of the spouse are not precisely estimated. The mortality plots from each of these models show results very similar to the base model results in Figure 2. ${ }^{28}$

${ }^{27}$ Specifically, the wealth polynomial is specified as
\[ \delta_{25}\left(\alpha_{0,1}+\alpha_{1,1} w p+\alpha_{2,1} w p^{2}\right)+\left(1-\delta_{25}\right)\left(\alpha_{0,2}+\alpha_{1,2}(w p-25)+\alpha_{2,2}(w p-25)^{2}\right), \] where the dummy variable $\delta_{25}$ is equal to 1 if the wealth percentile is less than 25 . One parameter is dropped $\left(\alpha_{0,2}\right)$ so that polynomials meet at the kink point.

${ }^{28} \mathrm{We}$ considered several specification checks and found little impact on the estimated mortality rates. We explored adding controls for demographic variables such as race, disability, retirement status, and region, and a dummy for the 1987 data. Most of these had the expected signs, though many are imprecisely estimated. We also used financial assets instead of net worth and estimated 12- and 24month mortality rates. 
FIGURE 3

Probability of Death for Head or Spouse Conditioning on Current Wealth: Low-Wealth Spline a. Probability by Age of Head and Selected Wealth Percentiles

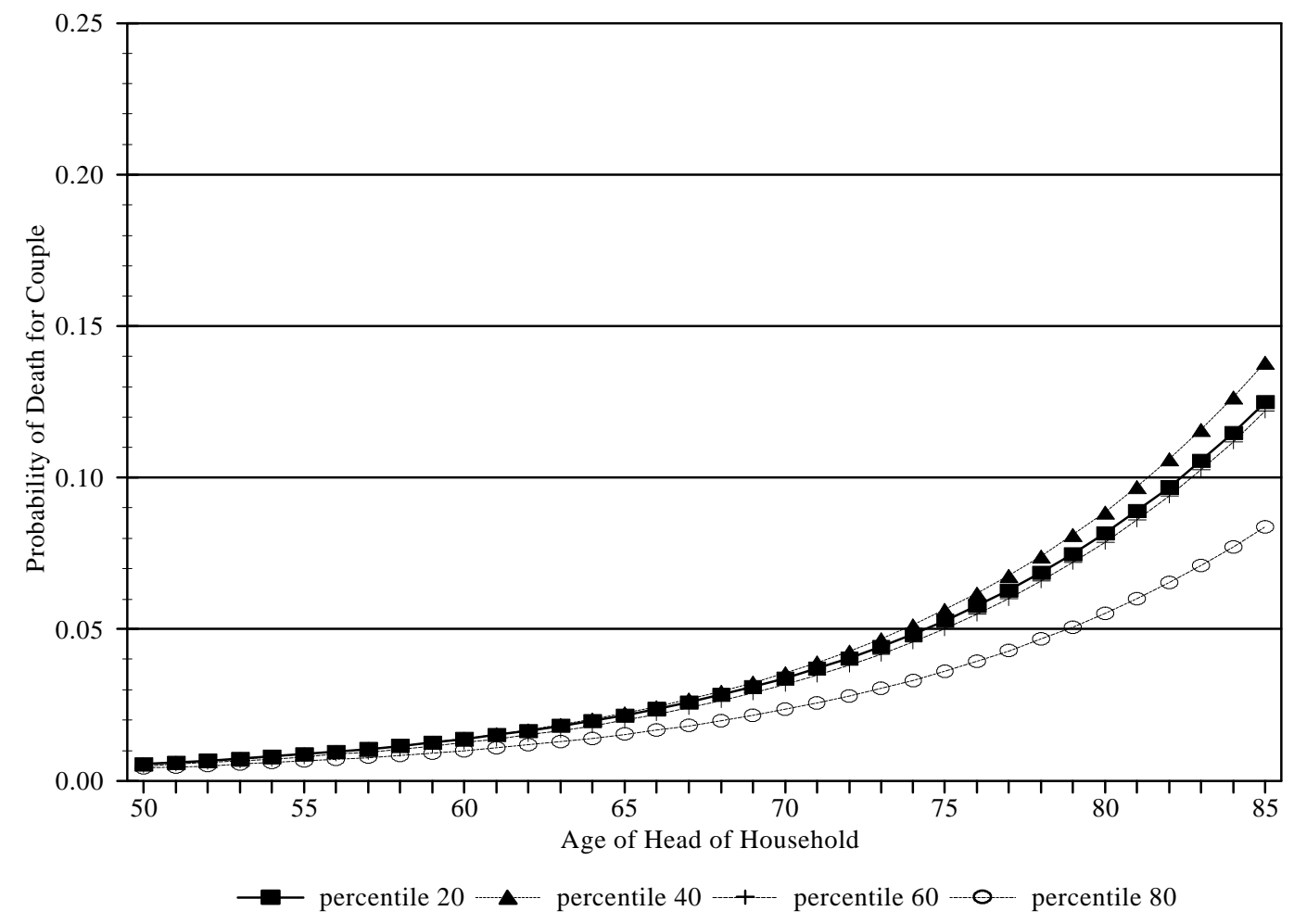

b. Probability by Wealth Percentile and Selected Ages

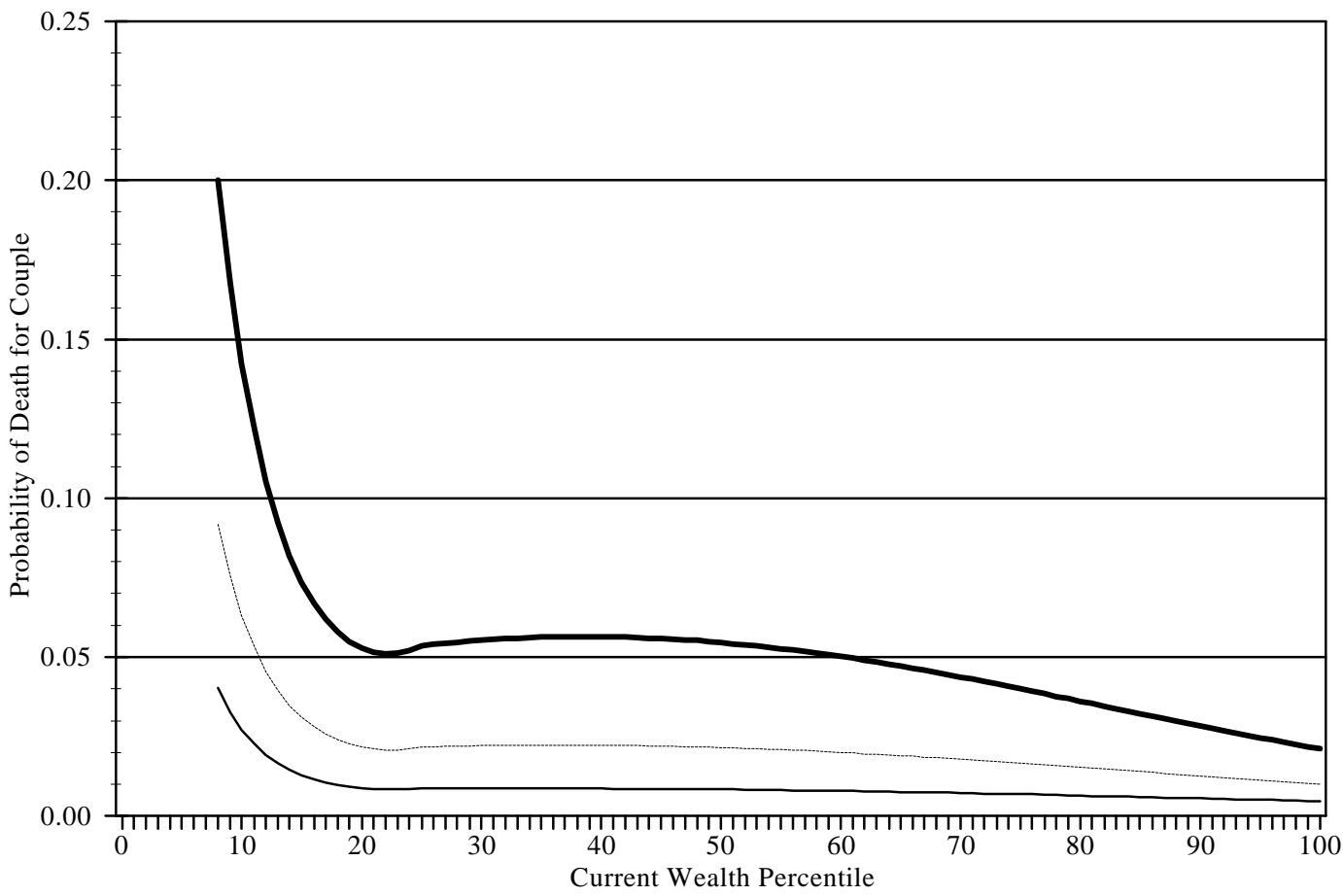

age $55 \longrightarrow$ age $65 \longrightarrow$ age 75 


\subsection{Conditioning on Wealth at Age 50}

Table 7 presents the parameter estimates when mortality rates are modeled as a function of age and wealth at a benchmark age. The model is estimated using maximum likelihood and the standard errors are calculated using the matrix of outer partials. ${ }^{29}$ The first model shows the results of the basic model with a polynomial in wealth percentile and age. Figure 4a plots the predicted mortality rates by age of head of household and wealth percentile at the benchmark age. This figure shows much stronger effects of wealth on mortality compared to conditioning on current wealth, especially at higher age levels. Because wealth is inversely related to mortality rates, individuals will move down the distribution of wealth over time. Accordingly, the results conditioning on current wealth will underestimate the extent to which lifetime resources affect mortality rates. ${ }^{30}$ Figure $4 \mathrm{~b}$ plots the predicted mortality rates for the base model as a function of current wealth percentile. These results show that the two empirical models can be thought of as different functional form assumptions. The predicted mortality rates closely match those based on the model conditioning on current wealth illustrated in Figure 2a. To further investigate the role of low wealth levels, a spline in wealth polynomial is estimated. As was found above, model (2) in Table 7 shows that the effects of the wealth polynomial are most concentrated at low wealth levels.

\footnotetext{
${ }^{29}$ Computation of the likelihood function is difficult because of the extremely nonlinear function that links current wealth percentiles to the percentiles at the benchmark age. In theory, for each observation one has to compute the wealth percentile at the benchmark age which corresponds to the observed percentile at the current age. This involves solving, by numerical methods, equation (1) for $y$, which in turns involves the valuation of an integral by quadrature methods. Because we use numerical derivatives to maximize the likelihood function, this procedure has to be repeated a number of times for each iteration of the maximization algorithm. To simplify this procedure, we adopted the following shortcut. For each percentile (from 1 to 100) at the benchmark age, we solve for the corresponding percentile at the current age (for all ages from 51 to 85). Because, on average, we have more than 100 observations per age group, we need to evaluate the percentile at the benchmark age for points that are not on the computed 100-point grid. These points are obtained by linear interpolation between the two surrounding points.

${ }^{30}$ The plots for the lowest wealth quartiles should be interpreted with caution as they represent out-of-sample predictions. The sample of persons surviving to age 70, for example, is likely to be drawn primarily from the higher levels of that cohort's initial wealth distribution. For example, only 8 percent of all persons 65-69 years old in the SIPP sample have wealth at the benchmark age which falls in the lowest quartile.
} 
TABLE 7

Parameter Estimates for Model Conditioning on Wealth at Age 50:

Married Couples

(1)

(2)

(3)

Noncompeting Risk Model

\begin{tabular}{|c|c|c|c|c|c|c|}
\hline WP & 0.584 & $(1.050)$ & & & & \\
\hline WP squared & 2.463 & $(0.703)$ & & & & \\
\hline WP cubed & -2.422 & $(0.742)$ & & & & \\
\hline Age of head $*$ WP & -0.509 & $(0.260)$ & -0.125 & $(0.209)$ & & \\
\hline Age of head $*$ WP squared & 0.313 & $(0.192)$ & 0.009 & $(0.169)$ & & \\
\hline Age of head & 0.301 & $(0.086)$ & 0.194 & $(0.063)$ & & \\
\hline Constant & -19.203 & $(4.302)$ & & & & \\
\hline $\mathrm{WP} \leq 25$ & & & -14.005 & $(3.408)$ & & \\
\hline $\mathrm{WP} \leq 25 * \mathrm{WP}$ & & & -5.209 & $(12.472)$ & & \\
\hline $\mathrm{WP} \leq 25 * \mathrm{WP}$ squared & & & 0.544 & $(24.883)$ & & \\
\hline $\mathrm{WP}>25 * \mathrm{WP}$ & & & 3.935 & $(8.922)$ & & \\
\hline $\mathrm{WP}>25 * \mathrm{WP}$ squared & & & 2.593 & $(12.152)$ & & \\
\hline \multicolumn{7}{|l|}{ Competing Risk Model } \\
\hline \multicolumn{7}{|l|}{ Probability of Death: Head } \\
\hline WP & & & & & -2.645 & $(0.697)$ \\
\hline WP squared & & & & & 4.047 & $(0.879)$ \\
\hline WP cubed & & & & & -1.838 & $(0.428)$ \\
\hline Age of head $*$ WP & & & & & 0.135 & $(0.100)$ \\
\hline Age of head $*$ WP squared & & & & & -0.133 & $(0.104)$ \\
\hline Age of head & & & & & 0.070 & $(0.020)$ \\
\hline Constant & & & & & -6.973 & $(1.315)$ \\
\hline \multicolumn{7}{|l|}{ Probability of Death: Spouse } \\
\hline WP & & & & & 0.555 & $(1.307)$ \\
\hline WP squared & & & & & 0.096 & $(1.524)$ \\
\hline WP cubed & & & & & -0.437 & $(0.624)$ \\
\hline Age of head $*$ WP & & & & & -0.117 & $(0.177)$ \\
\hline Age of head $*$ WP squared & & & & & 0.069 & $(0.171)$ \\
\hline Age of head & & & & & 0.130 & $(0.040)$ \\
\hline Constant & & & & & -14.200 & $(2.904)$ \\
\hline Number of observations & 7025 & & 7025 & & 7025 & \\
\hline Log likelihood & -2028.2 & & -2020.5 & & -2927.3 & \\
\hline
\end{tabular}

Note: These estimates are based on a discrete duration model where 4-month death probabilities are modeled using a logit specification. Standard errors are in parentheses. 
FIGURE 4

Probability of Death for Head or Spouse by Age of Head and Selected Wealth Percentiles Model Conditioning on Wealth at Age 50: Basic Model

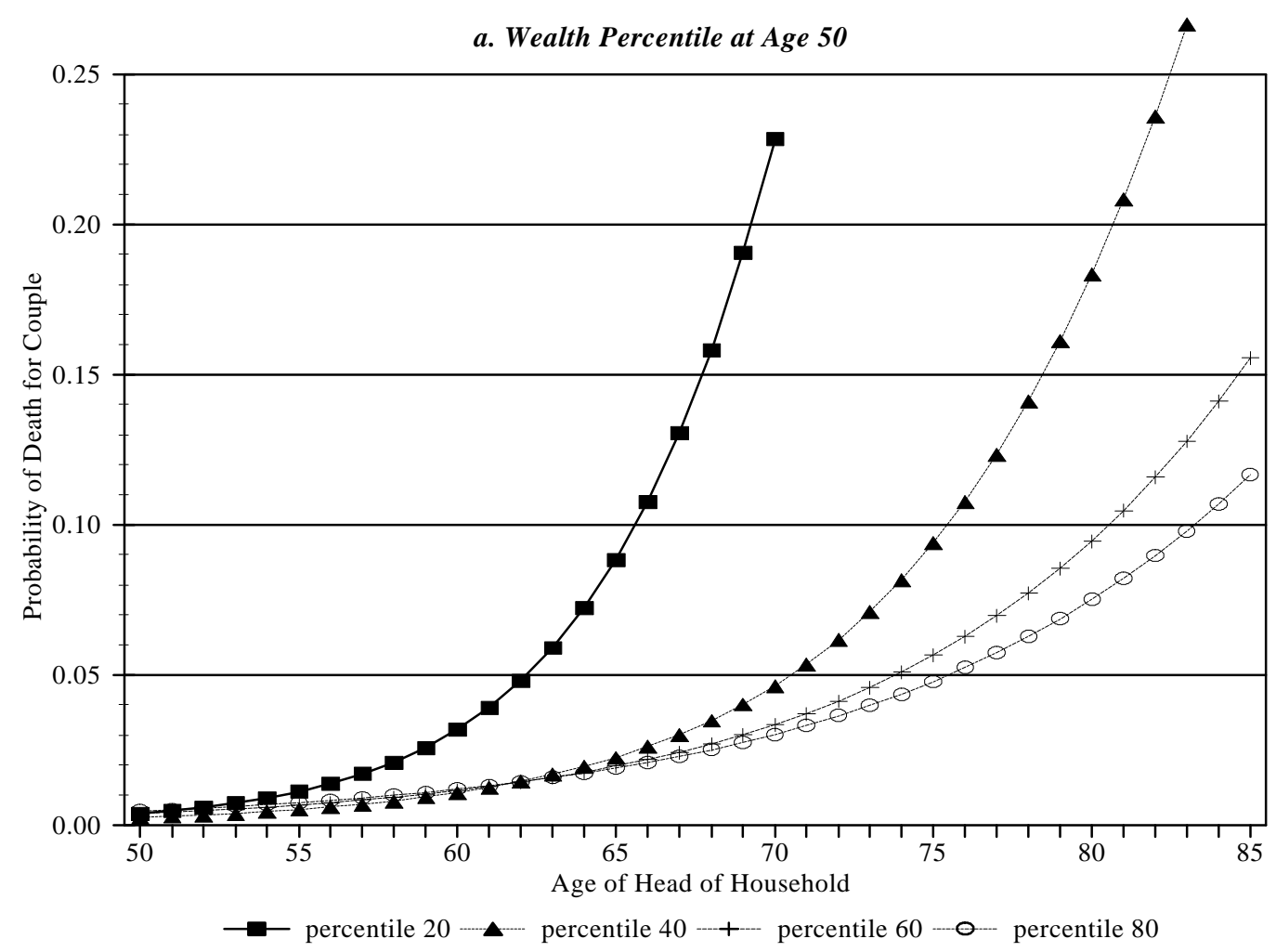

b. Wealth Percentile at Current Age

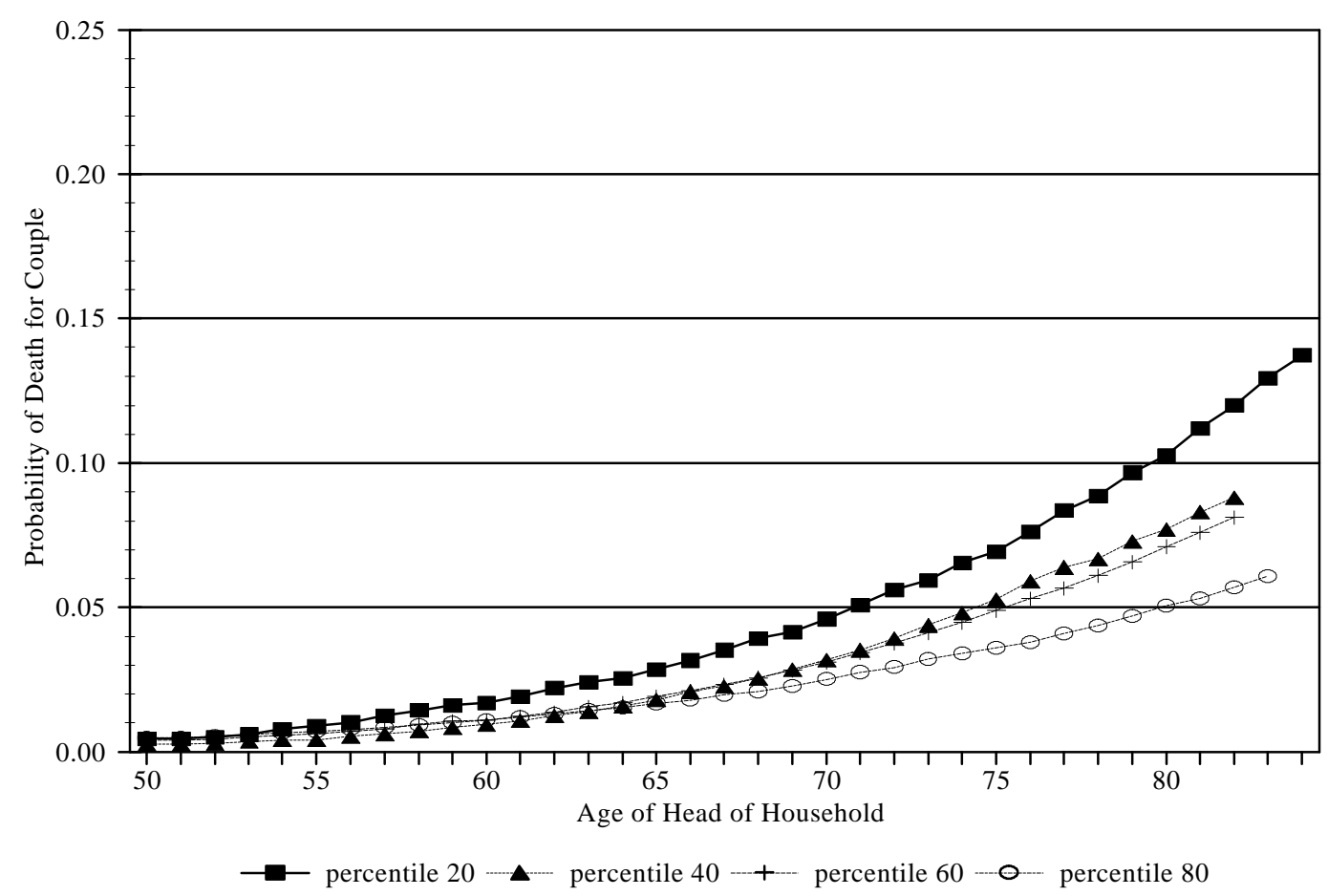


This is also presented in Figures 5a-5b. The competing risk model, as shown in specification (3), has results similar to that presented above. The determinants of the spouse's death rate are imprecisely estimated but the basic model implications are unchanged.

\section{CORRECTING WEALTH PROFILES}

The estimates from Section 7 are used to correct mean and median wealth profiles for sample selection generated by differential mortality. Although these estimates could, in principle, be applied to any cross-sectional dataset with wealth data, we use our SIPP sample. The steps used are as follows. First we construct the weight for each observation, using equation (2) or (3). These weights reflect the likelihood of someone having survived up to the observed age, given the estimates of the mortality rates from above. The weights are then used to create weighted profiles for mean and median wealth.

The mean corrected and uncorrected wealth profiles for the base model (specification (1) in Table 6) are shown in Figure 6. As expected, the effect of the sample selection increases with age, such that by age 75-79, the corrected profile reduces mean wealth by 15 percent. As a result of the skewness in the distribution of wealth, the correction to the median profile is slightly less than the correction to the mean profile. This evidence shows that differential mortality does make a difference in estimates of decumulation among the elderly. Our corrections are not as big as Shorrock's, who uses very crude actuarial rates and obtains very large corrections to wealth profiles.

Adding the spline for the polynomial in wealth at low wealth levels (model (2) in Table 6) showed more dramatic effects than the base model. This implies higher weights for those low-income families that survive to the current age, leading to larger corrections. At the same time, however, adding the low wealth spline reduced the effects of wealth on mortality at the higher wealth levels. This reduces the size of the corrections. The second force dominates, as shown in Figure 7, as the correction is slightly smaller for the 
FIGURE 5

Probability of Death for Head or Spouse by Age of Head and Selected Wealth Percentiles Model Conditioning on Wealth at Age 50: Low-Wealth Spline

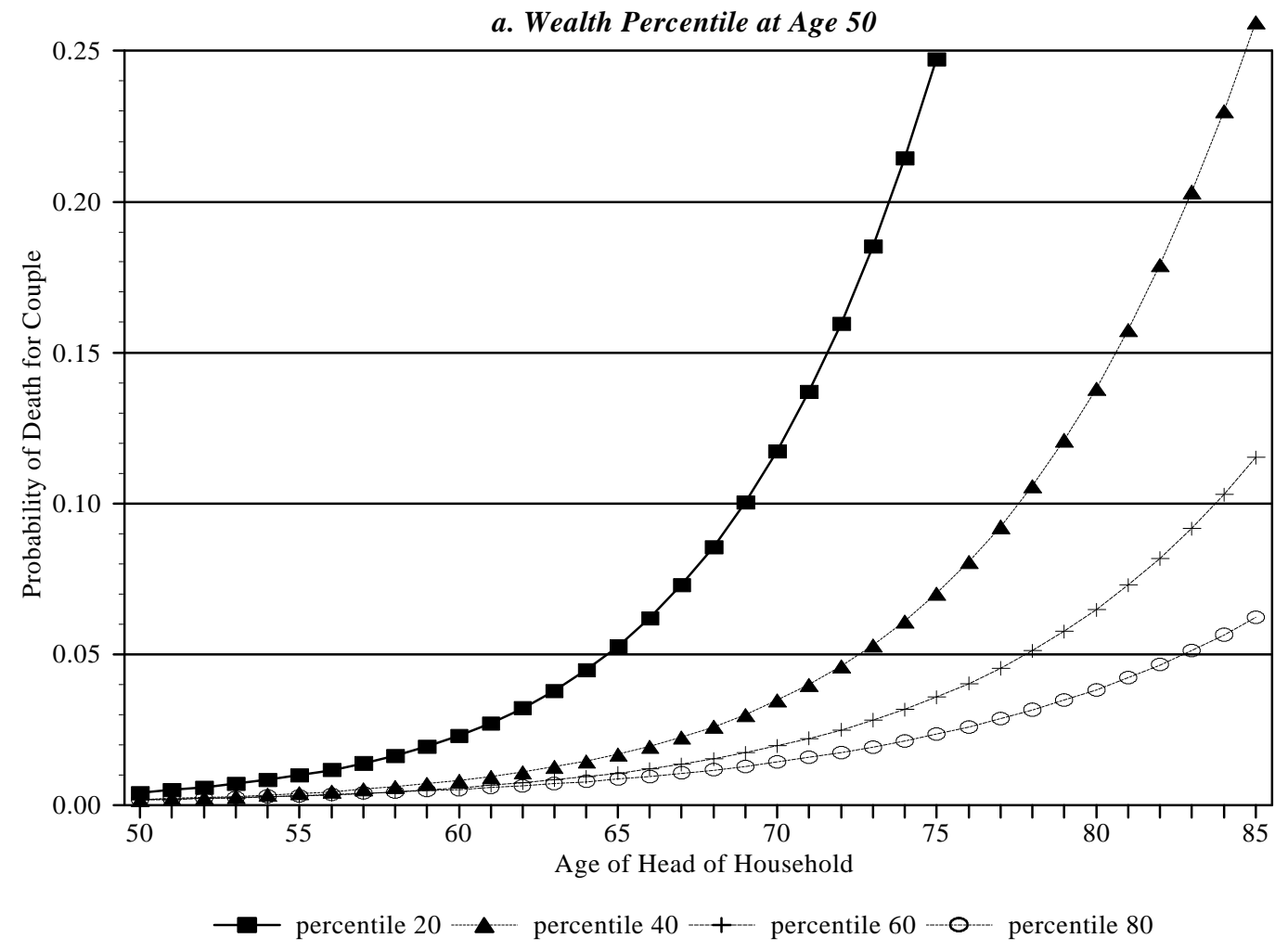

b. Wealth Percentile at Current Age

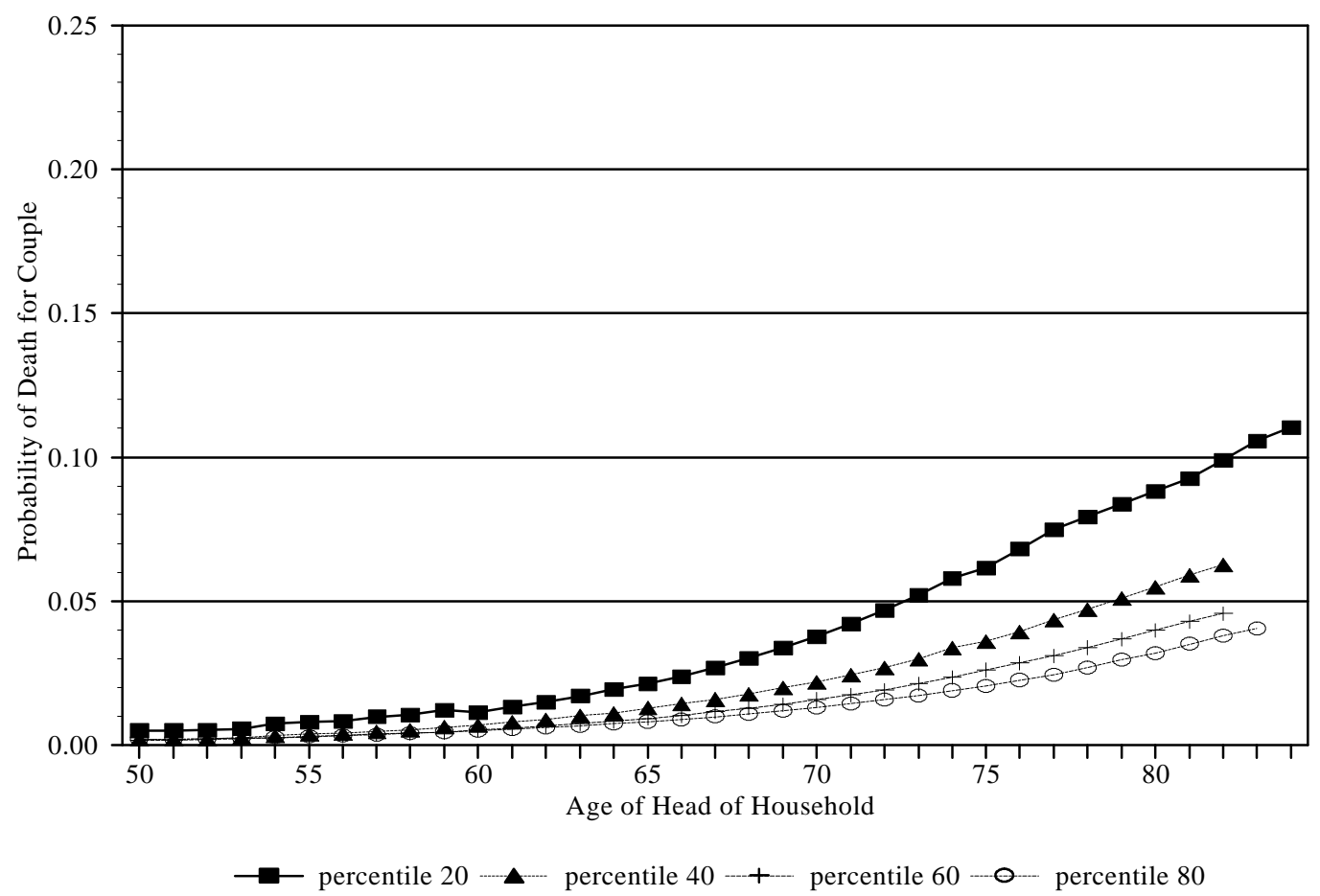


FIGURE 6

Corrected and Uncorrected Wealth Profile by Age of Head of Household

Model Conditioning on Current Wealth: Basic Model

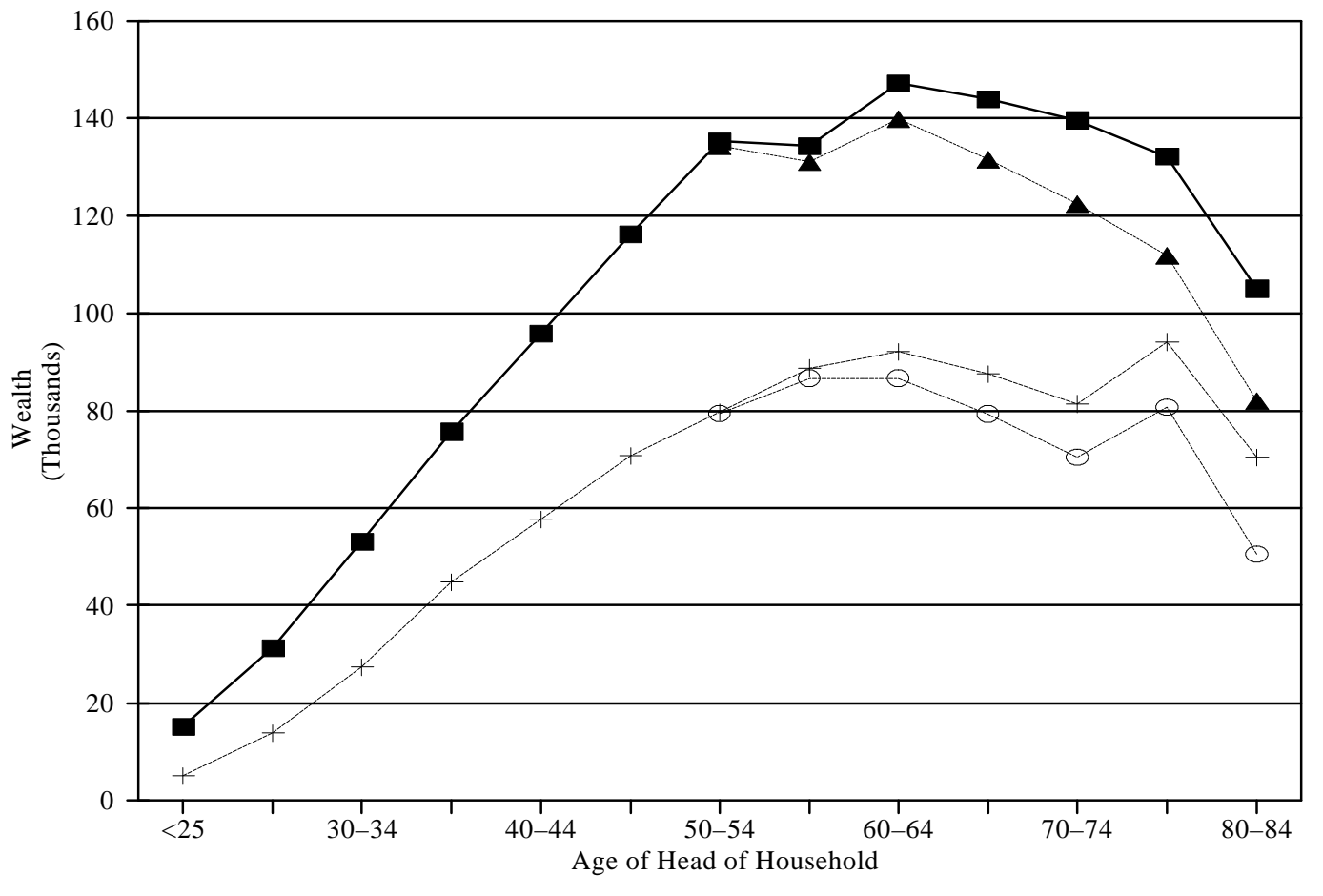

uncorrected mean $\quad \triangle$ corrected mean $\quad+\quad$ uncorrected median $-\odot$ corrected median

FIGURE 7

Corrected and Uncorrected Wealth Profile by Age of Head of Household Model Conditioning on Current Wealth: Low-Wealth Spline

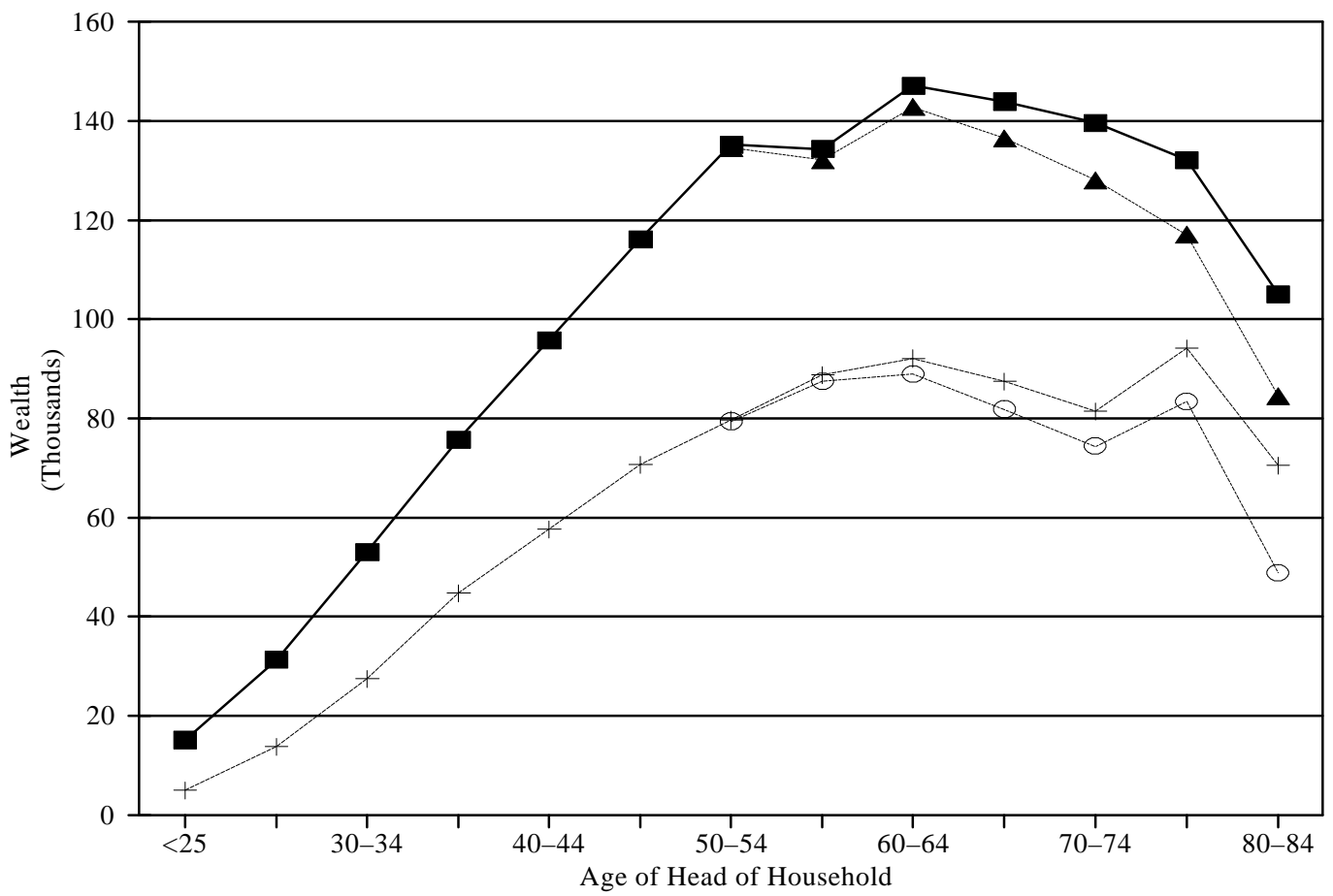

uncorrected mean

$\Delta$ corrected mean

+ uncorrected median

corrected median 
low wealth-spline model. The intuition here is that giving more weight to low-wealth individuals will not change the mean (or median) much since, by definition, they have low wealth levels and the distribution is very skewed..$^{31}$

The corrections for the model conditioning on wealth at age 50 show very similar results. Figure 8 shows the corrections for the base model and Figure 9 shows the corrections for the model with the low wealth spline. Comparing these to the earlier figures shows that the models have equivalent results for the magnitude of the corrections. We believe that the model conditioning on wealth at the benchmark age is more satisfactory in that the coefficients of the estimates are more easily interpretable.

\section{CONCLUSIONS}

The two main contributions of this paper are the identification and estimation of a relationship between wealth and mortality and the use of such a relationship to correct estimates of the wealth-age profile. The methodology we use considers some of the endogeneity problems that make the identification of the effect that wealth might have on mortality a nontrivial problem. In particular, we take into account the fact that if mortality depends on the relative position an individual or a household occupies in the wealth distribution, the relative position will depend, at each age, on the pattern of mortality at previous ages. Explicitly modeling this mechanism is what we propose in this paper.

We assume that mortality depends on the relative position in the wealth distribution at some benchmark age. Because wealth at the benchmark age is not observed, we have to impute it in a way that is consistent with our model. Although, at the estimation level, it is possible to condition on current (observed) wealth rather than wealth at the benchmark age, in order to use the estimates to correct the wealth-age profile, it is necessary to employ a relationship similar to that used for the model that

${ }^{31}$ The second spline is not statistically or economically significant. Setting the second spline to zero results in effects similar to those shown in Figure 7. 
FIGURE 8

Corrected and Uncorrected Wealth Profile by Age of Head of Household Model Conditioning on Wealth at Age 50: Basic Model

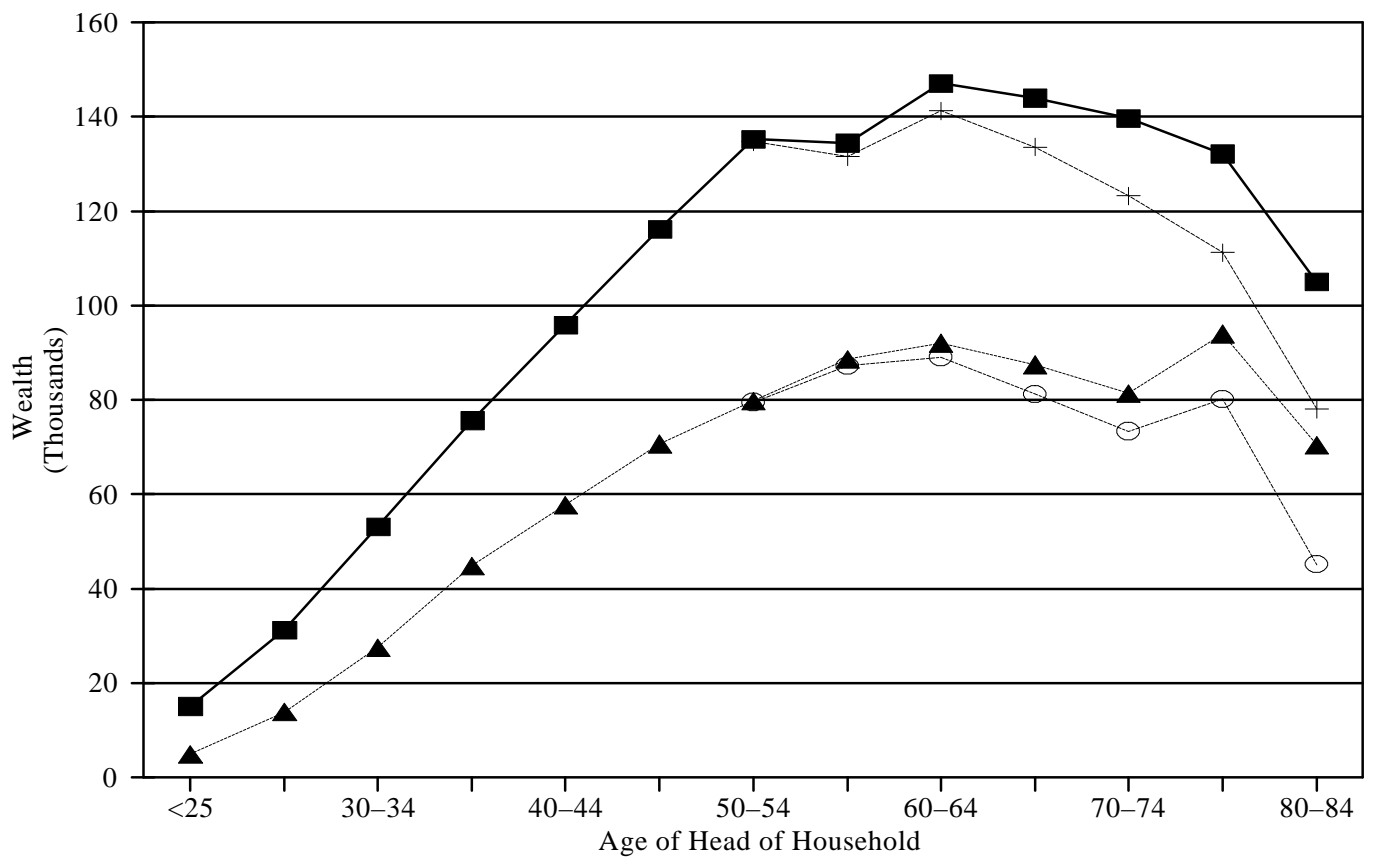

uncorrected mean

$\triangle$ corrected mean $\quad-\cdots$ uncorrected median $\odot-$ corrected median

FIGURE 9

Corrected and Uncorrected Wealth Profile by Age of Head of Household Model Conditioning on Wealth at Age 50: Low-Wealth Spline

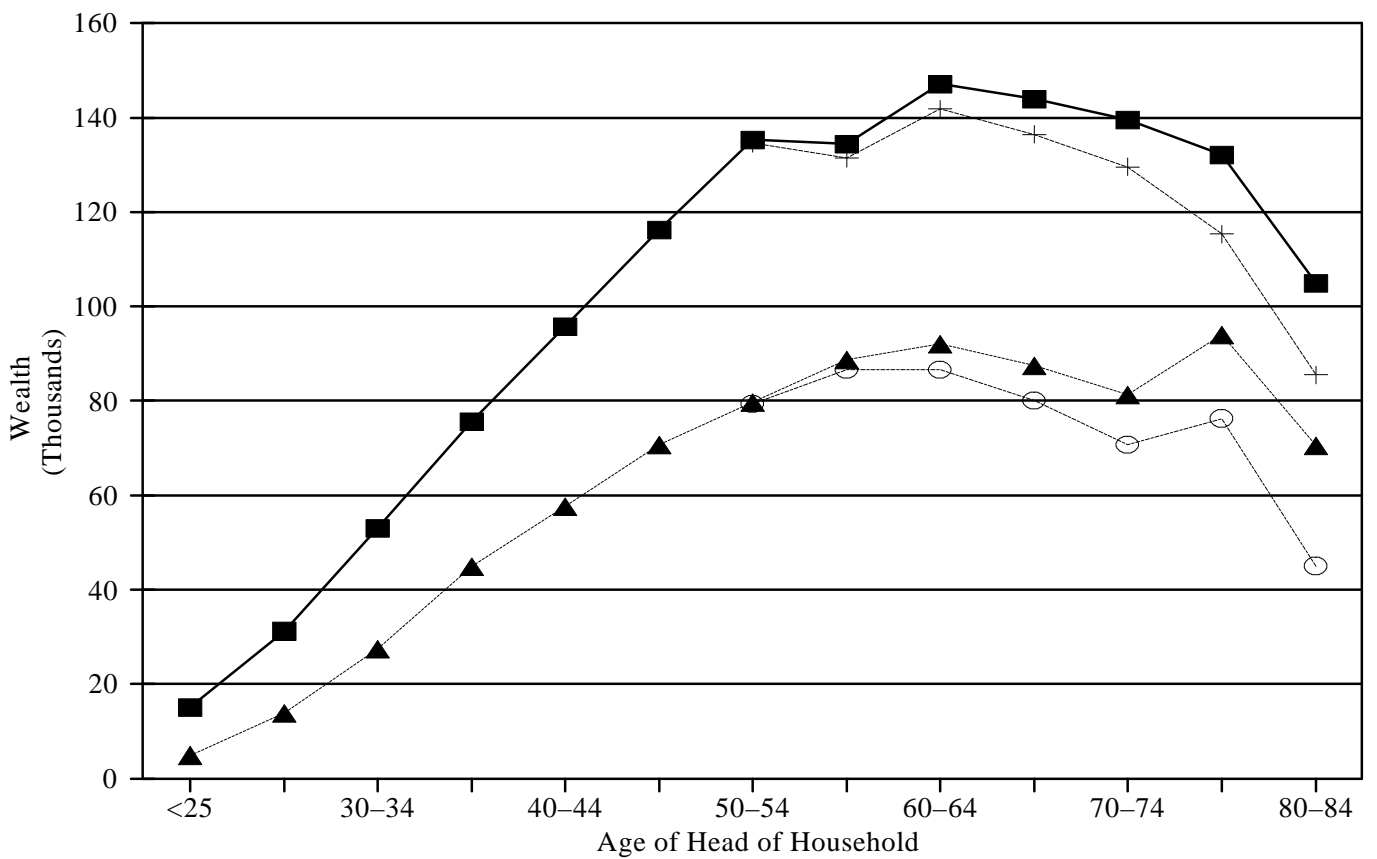

uncorrected mean

$\triangle$ corrected mean

+- uncorrected median $-\odot$ corrected median 
conditions on benchmark-age wealth. In the paper we show that the two models amount to a difference in functional form.

We have applied these techniques to a large panel of U.S. households and estimate significant effects of wealth on mortality. Although most of the differential in mortality is between the lowest 20 percent of the wealth distribution and the rest of the population, significant effects remain even for the higher part of the distribution. The estimated differential is large enough to show up in a statistically and economically significant correction for the estimated wealth-age profile.

To avoid modeling explicitly differences in mortality between married and single individuals (which are known to be important), we focused on married couples. Given the higher mortality and the lower level of wealth that characterizes single individuals, the relationship between wealth and mortality within this group is worth investigating. Although the limited size of our sample precluded such a study, it is an interesting topic for future research.

The correction of wealth-age profiles is a natural application of the results presented in this paper. Such a correction can provide useful insights into the debate about asset decumulation by the elderly. However, this is not the only application. Whenever one uses synthetic cohort techniques to estimate the dynamic behavior of consumption, income, or any other economic variable, either to estimate structural models or in data description, the corrections proposed in this paper are important. The techniques we describe can be used to correct the profiles for any variables from any dataset which contains information on wealth. 


\section{Appendix A}

\section{Adding Controls to the Model}

In this section, we describe how to infer the wealth distribution at the benchmark age if we assume that the survival probability is a function of age, wealth at the benchmark age, and a variable $Z$. Suppose the variable $Z$ takes on a discrete number $N_{z}$ of possible values, $\mathrm{z}_{1}, \mathrm{z}_{2}, \ldots, \mathrm{z}_{\mathrm{Nz}}$. The generalization to the continuous case is straightforward. If we denote $W P\left(a^{b}+k, y\right)$ to be the wealth percentile at age $a^{b}+k$ corresponding to wealth percentile $y$ at the benchmark age $a^{b}$, and $P S\left(a^{b}+i, x, z_{j}\right)$ to be the probability of surviving between ages $a^{b}+i$ and $a^{b}+i+1$ for somebody who was in percentile $x$ at age $a^{b}$, and for whom $Z=z_{j}, y$ solves the following expression,

$$
W P\left(a^{b}+k, y\right)=\frac{\sum_{j=1}^{N_{z}} \int_{0}^{y} \prod_{i=0}^{k-1} \operatorname{PS}\left(a^{b}+i, x, z_{j}\right) f^{0}\left(z_{j}, x\right) d x}{\sum_{j=1}^{N_{z}} \int_{0}^{1} \prod_{i=0}^{k-1} \operatorname{PS}\left(a^{b}+i, x, z_{j}\right) f^{0}\left(z_{j}, x\right) d x} .
$$

where $f^{0}\left(z_{j}, x\right)$ is the joint density of $Z$ and the wealth percentile at the benchmark age. In equation (A.1), we integrate out the covariate $Z$ because we need to know the wealth percentile among the total population, not within a $Z$ group. ${ }^{1}$ Notice that $f^{0}\left(z_{j}, x\right)=f^{0}\left(z_{j} \mid x\right)$ because the marginal distribution of the wealth percentiles at age $a^{b}$ is uniform between zero and unity by construction.

If the distribution of the control variable conditional on the wealth percentile at the benchmark age was known, the evaluation of equation (A.1) would be only marginally more difficult than the evaluation of equation (1) in section 4. Such a distribution, however, is not known. The only observable distribution is

${ }^{1}$ An alternative is to model the survival probability as a function of the wealth percentile at the benchmark age within your covariate group, $z_{j}$. With this assumption, we could use the expressions derived in Section 4. However, to implement this model, we would have to assign wealth percentiles not only within your age cohort but also within your group $z_{j}$. This would introduce significant error in the construction of the wealth percentiles due to small sample sizes in many cells. 
that at the current age. It is therefore necessary to infer the joint distribution at the benchmark age which is consistent with the observed distribution at the current age and with the model of differential mortality we are considering.

Given the conditional distribution of $Z$ at age $a^{b}+k$, one can infer the conditional distribution at age $a^{b}+k-1$ using the following relation:

$$
\mathrm{f}^{\mathrm{k}-1}\left(\mathrm{z}_{\mathrm{j}} \mid \mathrm{x}\right)=\frac{\mathrm{f}^{\mathrm{k}}\left(\mathrm{z}_{\mathrm{j}} \mid \mathrm{x}\right) / \operatorname{PS}\left(\mathrm{a}^{\mathrm{b}}+\mathrm{k}-1, \mathrm{x}, \mathrm{z}_{\mathrm{j}}\right)}{\sum_{\mathrm{s}=1}^{\mathrm{N}_{\mathrm{z}}} \mathrm{f}^{\mathrm{k}}\left(\mathrm{z}_{\mathrm{s}} \mid \mathrm{x}\right) / \operatorname{PS}\left(\mathrm{a}^{\mathrm{b}}+\mathrm{k}-1, \mathrm{x}, \mathrm{z}_{\mathrm{s}}\right)}
$$

Using equation (3) recursively, one can evaluate the conditional distribution of $Z$ at the benchmark age from its conditional distribution at the current age.

If the available sample was very large, it would be possible to estimate the conditional distribution of $Z$ at the current age completely nonparametrically by looking at the relative frequency. Given the size of the available sample, however, one would need to impose some structure and estimate the parameters of the conditional distribution at the current age simultaneously with the other parameters of the model. 


\section{References}

Attanasio, Orazio P. 1993. "A Cohort Analysis of Life-Cycle Accumulation of Financial Assets." Richerche Economiche 47:323-354.

Blinder, Alan S., Roger H. Gordon, and Donald E. Wise. 1983. "Social Security, Bequests, and the LifeCycle Theory of Saving: Cross-Sectional Tests.” In The Determinants of National Saving and Wealth, ed. Franco Modigliani and Richard Hemming, pp. 89-122. New York: St. Martin’s.

Burkhauser, Richard, Karen C. Holden, and Daniel Feaster. 1988. "Incidence, Timing, and Events Associated with Poverty: A Dynamic View of Poverty in Retirement.” Journal of Gerontology 43(2): S46-S52.

Curtin, Richard T., F. Thomas Juster, and James N. Morgan. 1989. "Survey Estimates of Wealth: An Assessment of Quality.” In Measurement of Savings, Investment, and Wealth, ed. R. E. Lipsey and H. S. Tice. Chicago: University of Chicago Press.

Davies, J. B. 1981. “Uncertain Lifetime, Consumption and Dissaving in Retirement.” Journal of Political Economy 86: 561-577.

Duleep, Harriet Orcutt. 1987. "Measuring the Effect of Income on Adult Mortality Using Longitudinal Administrative Record Data.” Journal of Human Resources 21 (2): 238-251.

Hurd, Michael D. 1990. "Research on the Elderly: Economic Status, Retirement, and Consumption and Saving." NBER reprint no. 1444.

Hurd, Michael, and Kathleen McGarry. 1993. "Evaluation of Subjective Probability Distributions in the HRS.” NBER Working Paper \#4560, December.

Hurd, Michael D., and David A. Wise. 1989. “The Wealth and Poverty of Widows: Assets Before and After the Husband's Death.” In The Economics of Aging, ed. David A. Wise. Chicago: University of Chicago Press. 
Jianakoplos, Nancy Ammon, Paul L. Menchik, and F. Owen Irvine. 1989. "Using Panel Data to Assess the Bias in Cross-Sectional Inferences of Life-Cycle Changes in the Level and Composition of Household Wealth.” In The Measurement of Saving, Investment, and Wealth, ed. Robert E. Lipsey and Helen S. Tice. Chicago: University of Chicago Press.

Kalbfleisch, J. D., and R. L. Prentice. 1980. The Statistical Analysis of Failure Time Data. New York: John Wiley and Sons.

King, M. A., and L-D. L. Dicks-Mireaux. 1982. “Asset Holdings and the Life-Cycle.” Economic Journal 92 (June): 247-267.

Kitagawa, Evelyn M., and Philip M. Hauser. 1973. Differential Mortality in the United States: A Study in Socioeconomic Epidemiology. Cambridge: Harvard University Press.

Menchik, Paul. 1993. "Economic Status as a Determinant of Mortality among Black and White Older Males-Does Poverty Kill?” Population Studies 47(3): 427-436.

Mirer, Thad W. 1979. “The Wealth-Age Relation among the Aged.” American Economic Review (June): 435-443.

Modigliani, D., and A. Ando. 1957. "Tests of the Life-Cycle Hypothesis of Savings." Bulletin of the Oxford Institute of Economics and Statistics 19: 99-124.

Modigliani, F., and R. Brumberg. 1954. "Utility Analysis and the Consumption Function: An Interpretation of Cross-Section Data.” In Post-Keynesian Economics, ed. K. Kurihara. New Brunswick, N.J.: Rutgers University Press.

Shorrocks, A. F. 1975. “The Age-Wealth Relationship: A Cross-Section and Cohort Analysis.” Review of Economics and Statistics: 155-163.

Social Security Administration. 1992. Life Tables of the United States Social Security Area, 1900-2080. SSA Publication no. 11-11535. 